\title{
High Performance Adaptive Maximum Power Point Tracking Technique for Off-Grid Photovoltaic Systems
}

Mohamed Mosaad ( $\sim$ m_i_mosaad@hotmail.com )

Yanbu Industrial College (YIC), Kingdom of Saudi Arabia

Fahd Banakhr

Royal Commission for Jubail and Yanbu

\section{Research Article}

Keywords: PV, adaptive maximum power point tracking, harmony search optimization, DC-DC converter

Posted Date: January 15th, 2021

DOI: https://doi.org/10.21203/rs.3.rs-145776/v1

License: (c) (i) This work is licensed under a Creative Commons Attribution 4.0 International License.

Read Full License 


\title{
High Performance Adaptive Maximum Power Point Tracking technique for off-Grid Photovoltaic
}

\author{
Systems \\ Fahd A. Banakher ${ }^{1}$ and Mohamed I. Mosaad ${ }^{2 * *}$ \\ ${ }^{1,2}$ Yanbu Industrial College (YIC), Kingdom of Saudi Arabia \\ ${ }^{*}$ Corresponding author email m_i_mosaad@ hotmail.com
}

\begin{abstract}
Solar photovoltaic (PV) energy has met great attention in the electrical power generation field for its many advantages in both on and off-grid applications. The requirement for higher proficiency from the PV system to reap the energy requires maximum power point tracking techniques (MPPT). This paper presents an adaptive MPPT of a stand-alone PV system using an updated PI controller optimized by harmony search (HS). A lockup table is formed for the temperature and irradiance with the corresponding voltage at MPP ( $\left.V_{M P P}\right)$. This voltage is considered as the updated reference voltage required for MPP at each temperature and irradiance. The difference between this updated reference voltage at MPP and the variable PV voltage due to changing the environmental conditions is used to stimulate PI controller optimized by HS to update the duty cycle (D) of the DC-DC converter. Another lockup table is formed with the temperature, irradiance and the corresponding duty cycle at MPP to convert this MPP technique into an adaptive one. An experimental implementation of the proposed adaptive MPPT is introduced to test the validity of the simulation results obtained at different irradiance and temperature levels.
\end{abstract}

Index terms: PV, adaptive maximum power point tracking, harmony search optimization, DC-DC converter.

\section{INTRODUCTION}

Due to the environmental difficulties and the great increase in energy demands, there has become a global and urgent need to generate power from renewable energy sources (RES). This urgent need to use and implement RES is due to several factors including but not limited to clean and non-polluted production of energy, continuity generations as these RES will not be depleted. Many RES with large penetration into the electrical networks were used and implemented based on many types of RES. Wind energy, fuel cell and photovoltaic (PV) were used in many applications either on or off-grid applications[1-3]. Some of these RES may be connected to form hybrid RES. These hybrid systems are used for on and off-grid applications [4]. 
PV systems are widely spread as one of RES. Growth of PV systems and solar energy PV systems had become common in many off and on-grid applications with expected generating level PV up to 1 TW in $2021[5]$.

The initial cost and the subsequent generating unit (kW.hr) cost of PV systems is still relatively high compared to the classical fuel. This increase in costs has led to a significant tendency to use the available output power from PV without directions to create new PV systems, if possible. One of the well-known techniques for using the available power extracted from PV systems is maximum power point tracking (MPPT).

MPPT of PV systems means controlling and adapting the output of generated power from PV to MPP available from PV at certain surrounding environmental conditions. MPPT is based on control and drive the duty cycle (D) of the DC-DC converter connecting the DC output of PV system feeding the load in off-grid applications or feeding an inverter in on-grid applications [6-10]. The output power of the PV system mainly relies on the surrounding temperature and the irradiance. MPPT techniques are to force the characteristics of the PV system to operate at the MPP to exploit the available energy from PV at a certain temperature and irradiance conditions by regulating the duty cycle of the DC-DC converter. Many MPPT algorithms were proposed, from them perturb and observation $(\mathrm{P} \& \mathrm{O})$ was used in many applications [3]. $\mathrm{P} \& \mathrm{O}$ is a very simple technique and easy to be implemented [11]. P\&O is affected largely by the perturb step value for both transient and steady-state operating conditions. That calls for adaptive regulation of the perturbation step as in [12-13]. Different procedures were applied to convert the MPPT into adaptive MPPT [14-17]. These adaptive techniques suffered from high computational load and well-known by the users to adapt perturb step size.

Incremental conductance method (IC) with endeavors to overcome the problems that appear when using P\&O MPPT technique was presented in [18-20]. IC gave a better performance than P\&O in the transient periods associated with rapid changes in the environmental conditions. Some modifications are applied to improve the IC method by adjusting PI controllers with the capability to modify the duty cycle of the DCDC converters. The challenges in these modifications are to determine the PI controller parameters and how to adapt them quickly with variations in the environmental conditions. For tuning the PI controller parameters, many optimization techniques were introduced. Genetic algorithms, particle swarm optimization, cuckoo search and harmony search (HS) were introduced for optimal tuning of PI controller parameters for many power systems applications [21-26]. These optimization techniques succeed at the optimal tuning of the PI controller parameters off-line. With varying operating conditions, the optimized PI controller parameters could not condemn the optimality, if they are not returned. Adaptive algorithms should be introduced to convert PI controller into an optimal one. Artificial neural network is introduced to convert 
adaptive PI controllers into adaptive one as in [26-27]. However these techniques acquire high experience for users, and much training data to assure the accuracy of the systems.

In this paper, a simple and robust adaptive MPPT technique is proposed. The PV curve of the PV system is plotted and verified practically. A lockup table is formed for different values of irradiance, temperature and the corresponding voltage at MPP ( $\left.\mathrm{V}_{\text {MPP_ref }}\right)$. This MPP voltage is taken as the updated reference and compared to the varied PV voltage due to the variation of irradiance and temperature. The error between the reference updated voltage and the PV voltage represents the input to the PI controller. This error is minimized using HS optimization. This process is repeated 30 times to obtain the optimized PI controller parameters with the corresponding duty cycles required for MPPT at each temperature and irradiance. A second lockup table is formed with the irradiance, temperature and the corresponding duty cycle required for MPPT. This table is used to achieve adaptive MPPT without using PI controller. These data were used to build up a practical circuit to achieve the adaptive MPPT technique proposed. A simple microcontroller is used with the data in the second table to dive the DC-DC converter with the updated duty cycle at each irradiance and temperature to assure adaptive MPPT at different temperatures and irradiances.

\section{Problem Formulation}

The proposed system, Fig. 1, comprises a PV module connected to a DC-DC converter feeding a load. The duty cycle ratio of the DC-DC converter is controlled using an optimized PI controller to maintain MPP of the PV system. A lockup table (table 1) consists of the temperature, irradiance and the corresponding voltage at MPP obtained from the characteristics is formed. This table is used for updating the reference voltage ( $\left.\mathrm{V}_{\text {MPP_ref }}\right)$ for MPP at each temperature and irradiance. The PV voltage $\left(\mathrm{V}_{\mathrm{pv}}\right)$ is sensed and compared to the updated reference voltage. This error is minimized by HS optimization technique and used to stimulate the DC-DC chopper to track MPP [28-29].

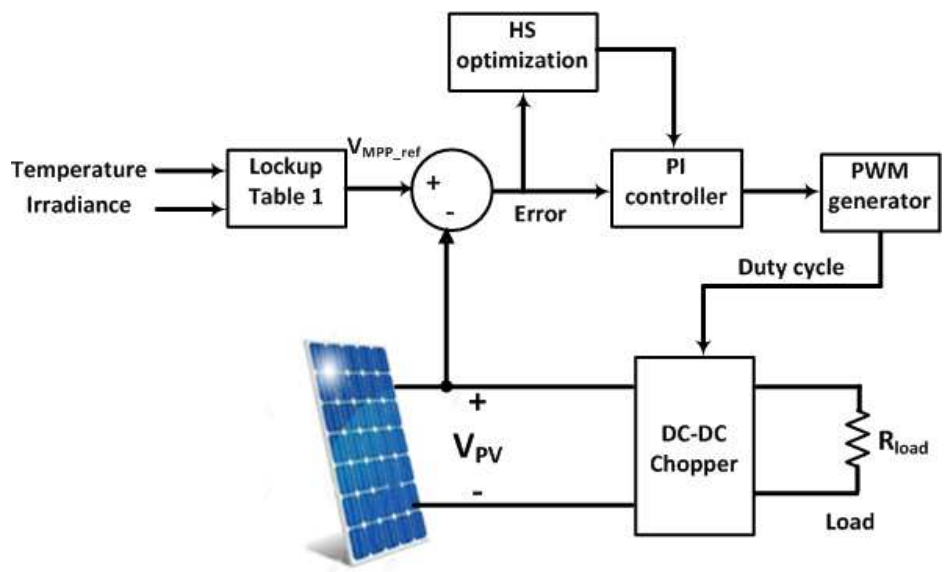


Fig.1. System under study.

a- PV modeling

The PV equivalent circuit is given in Fig. 2. This circuit comprises a light-dependent current source with a shunted diode [6-7]. The current produced by this current source is directly proportional to the light dropped on the PV. RS and Rp are series and shunt resistances of PV respectively.

In this paper, the EBS solar module is used and the specifications of this module are given in Table 1 at standard conditions of $25^{\circ} \mathrm{C}$ temperature and irradiance of $1000 \mathrm{~W} / \mathrm{m}^{2}$

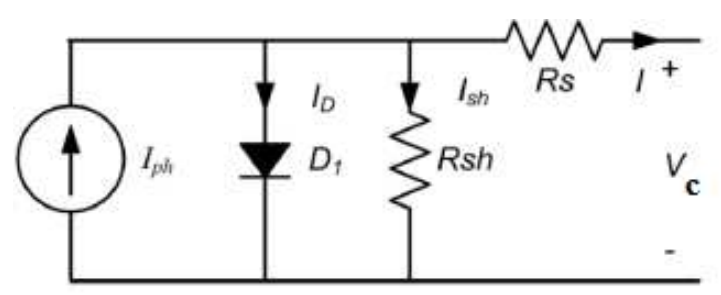

Fig.2. Solar cell equivalent circuit

Table 1: Specifications of EBS solar module at standard conditions.

\begin{tabular}{llll}
\hline Open circuit voltage & $\mathrm{V}_{\mathrm{OC}}$ & 21.8 & $\mathrm{~V}$ \\
Short circuit current & $\mathrm{I}_{\mathrm{sc}}$ & 2.23 & $A$ \\
Voltage at max. power & $\mathrm{V}_{\mathrm{m}}$ & 17.2 & $\mathrm{~V}$ \\
Current at max. power & $\mathrm{I}_{\mathrm{m}}$ & 2.04 & A \\
Maximum power & $\mathrm{P}_{\mathrm{m}}$ & 35 & $\mathrm{~W}$ \\
\hline
\end{tabular}

\section{b- PI controller design}

The updated reference voltage, $V_{M P P_{-}}$ref represents the voltage at which MPP is attained is used and compared to the current PV voltage, $V_{p v}$. The difference between these two voltages, ev represents the error used to drive PI controller. An objective function, $J$ is formed based on the integral square of error of ev that can be defined as:

$J=\int_{0}^{t}\left((e v(t))^{2} d t\right.$

HS optimization technique is used for minimizing this objective function and determine the optimal PI control parameters at each irradiance and temperature.

\section{c-Harmony search optimization}


The first step in HS is the initialization of the two PI control parameters by supposing random values of them. Then the fitness function J, given in (1) is determined with these random values. Then the Harmony Memory (HM) is set as in (2)

$$
H M=\left[\begin{array}{cc}
K_{p}^{1} & K_{i}^{1} \\
K_{p}^{2} & K_{i}^{2} \\
\cdot & \cdot \\
\cdot & \cdot \\
\cdot & \cdot \\
K_{p}^{H M S} & K_{i}^{H M S}
\end{array}\right]
$$

The HM matrix contains two columns each of them is for the PI controller parameters $\left(\mathrm{K}_{\mathrm{p}}, \mathrm{K}_{\mathrm{i}}\right)$. Each row in this matrix is the enhanced harmony vector based on the harmony memory considering rate (HMCR) and pitch adjusting rate (PAR). The updated harmony vector $x_{i}^{n+1}$ of the current harmony vector $x_{i}^{n}$ is calculated as:

$$
x_{i}^{n+1}=x_{i}^{n}+\operatorname{rand} * B W
$$

where rand is a random value between $(0,1)$ and $B W$ is an arbitrary distance bandwidth.

The updating process is done again till reaching the minimum possible value for the objective function $J$ or reaching the maximum search iteration numbers, Fig. 3 [30].

\section{Simulation RESULTS}

\section{a- Experimental verification of P-V and I-V characteristics}

The experimental verification of P-V and I-V characteristics of the solar cell used is given in Fig.4 a and b at $25^{\circ} \mathrm{C}$ and $1000 \mathrm{~W} / \mathrm{m}^{2}$. This experimental verification is used to verify the modeling results as this model will be used many times at different environmental conditions to determine the voltage at MPP which is, in turn, the updating the reference voltage ( $\mathrm{V}_{\mathrm{MPP} \_}$ref $)$.

The model is simulated for 30 cases, each case has a certain temperature and irradiance to get the voltage at MPP from the P-V characteristics. The temperature is taken from 22 to $37{ }^{\circ} \mathrm{C}$ with a step of $3{ }^{\circ} \mathrm{C}$ while the irradiance is taken from 200 to $1000 \mathrm{~W} / \mathrm{m}^{2}$ with a step of $200 \mathrm{~W} / \mathrm{m}^{2}$, Table 2 . From these data, the reference voltage is updated at each irradiance and temperature. 


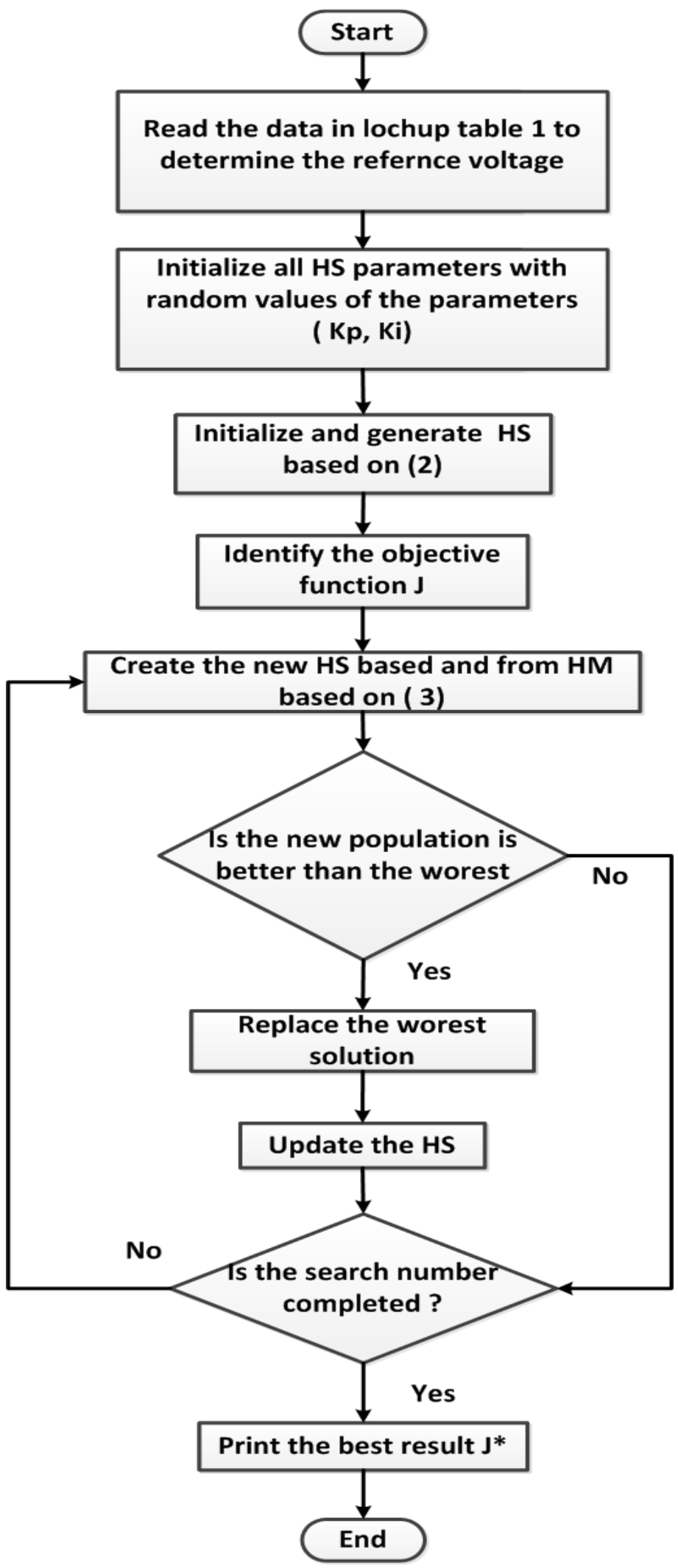

Fig. 3 HS optimization flow chart. 

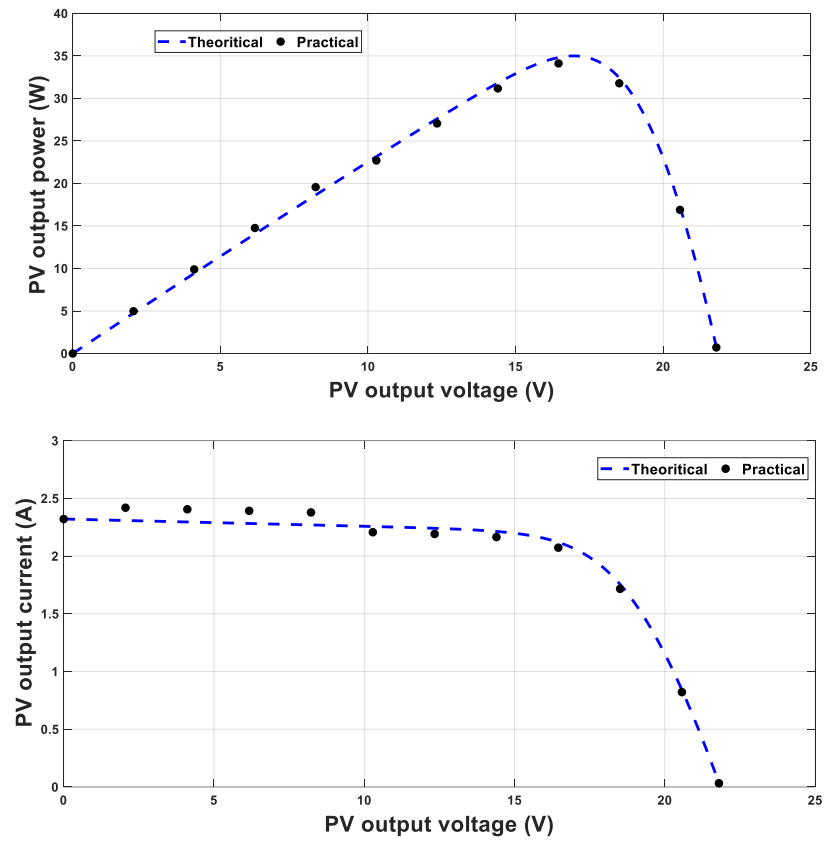

a- P-V characteristics b- I-V characteristics

Fig.4 Experimental verification of solar cell characteristics.

\section{b- Harmony search optimization technique}

Due to the temperature and irradiance variations, the PV output voltage will change to new values different from the required values for MPP. These variables PV voltages will be compared to the voltage required for MPPT at these environmental conditions as in table 2. The error between the PV voltage and the updated reference voltage based on Table 2 is used to drive PI controller to produce the duty cycle required for the converter. HS optimization algorithm is used for minimizing the objective function given in (1) then determine the optimal PI controller parameters. HS optimization is used 30 times to obtain the optimal PI controller parameters for each case. The convergences of the first three cases are given in Fig.5.

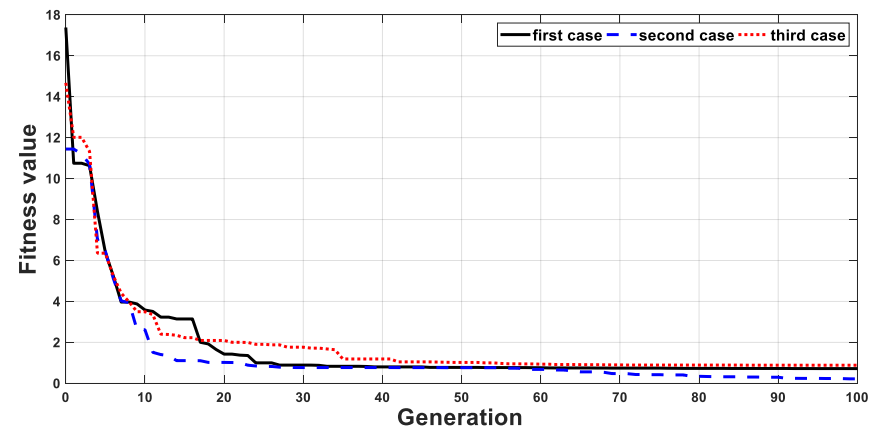

Fig.5 Convergence of objective function using HS

The optimized PI controller parameters using HS for the 30 cases proposed are given in Table 2. 
Table 2: Temperature, irradiance PV voltage and power at MPP and the control parameters

\begin{tabular}{|c|c|c|c|c|c|c|}
\hline \multirow[t]{2}{*}{ Point } & \multirow[t]{2}{*}{$\operatorname{Tem}^{\circ} \mathrm{C}$} & \multirow{2}{*}{$\begin{array}{l}\text { Irra. } \\
\mathrm{W} / \mathrm{m}^{2}\end{array}$} & \multirow[t]{2}{*}{$\mathrm{V}_{\text {MPP }}(\mathrm{V})$} & \multirow[t]{2}{*}{$\mathrm{P}_{\text {MPP }}(\mathrm{W})$} & \multicolumn{2}{|c|}{ Optimized PI controller } \\
\hline & & & & & $\mathrm{Kp}$ & $\mathrm{Ki}$ \\
\hline 1 & 22 & 200 & 16.470 & 5.5959 & 13.6819 & 40.191 \\
\hline 2 & 25 & 200 & 16.261 & 5.5367 & 8.0478 & 39.300 \\
\hline 3 & 28 & 200 & 16.0533 & 5.4764 & 9.6567 & 15.231 \\
\hline 4 & 31 & 200 & 15.7406 & 5.4153 & 8.0437 & 10.100 \\
\hline 5 & 34 & 200 & 15.5321 & 5.3533 & 12.4134 & 32.083 \\
\hline 6 & 37 & 200 & 15.3236 & 5.2901 & 3.0874 & 18.891 \\
\hline 7 & 22 & 400 & 17.3042 & 13.159 & 7.6269 & 18.107 \\
\hline 8 & 25 & 400 & 16.9915 & 12.9979 & 3.2227 & 16.234 \\
\hline 9 & 28 & 400 & 16.783 & 12.8354 & 15.1622 & 44.448 \\
\hline 10 & 31 & 400 & 16.5745 & 12.6713 & 17.4222 & 28.625 \\
\hline 11 & 34 & 400 & 16.2618 & 12.5065 & 7.0155 & 19.456 \\
\hline 12 & 37 & 400 & 16.0533 & 12.3411 & 13.7107 & 18.919 \\
\hline 13 & 22 & 600 & 17.5127 & 20.7386 & 5.8830 & 14.178 \\
\hline 14 & 25 & 600 & 17.2 & 20.4769 & 10.6126 & 34.590 \\
\hline 15 & 28 & 600 & 16.9915 & 20.2138 & 16.6485 & 37.350 \\
\hline 16 & 31 & 600 & 16.783 & 19.9486 & 11.9498 & 26.869 \\
\hline 17 & 34 & 600 & 16.4703 & 19.6823 & 6.7062 & 27.971 \\
\hline 18 & 37 & 600 & 16.2618 & 19.4163 & 5.9845 & 37.564 \\
\hline 19 & 22 & 800 & 17.5127 & 28.1916 & 9.0519 & 21.695 \\
\hline 20 & 25 & 800 & 17.3042 & 27.8289 & 8.452 & 29.513 \\
\hline 21 & 28 & 800 & 16.9915 & 27.467 & 7.19 & 16.450 \\
\hline 22 & 31 & 800 & 16.783 & 27.1036 & 11.16 & 40.045 \\
\hline 23 & 34 & 800 & 16.5745 & 26.7383 & 14.85 & 22.717 \\
\hline 24 & 37 & 800 & 16.366 & 26.371 & 8.486 & 12.548 \\
\hline 25 & 22 & 1000 & 17.408 & 34.923 & 8.587 & 19.535 \\
\hline 26 & 25 & 1000 & 17.2 & 35 & 2.497 & 13.986 \\
\hline 27 & 28 & 1000 & 16.991 & 34.539 & 9.488 & 31.442 \\
\hline 28 & 31 & 1000 & 16.783 & 34.076 & 5.803 & 15.047 \\
\hline 29 & 34 & 1000 & 16.4703 & 33.6139 & 6.3504 & 22.051 \\
\hline 30 & 37 & 1000 & 16.2618 & 33.1505 & 13.0738 & 29.685 \\
\hline
\end{tabular}

c- Adaptive maximum power technique proposed

The proposed technique PI-HS for MPPT will be compared to P\&O and IC methods to study the effectiveness of the proposed method. At the standard conditions of $25^{\circ} \mathrm{C}$ and $1000 \mathrm{~W} / \mathrm{m}^{2}$ (point 26 in the 
table), the MPP with P\&O, IC and PI-HS are plotted in Fig.6. The performance of the PV system with the proposed technique surplus the performance with $\mathrm{P} \& \mathrm{O}$ and IC methods.

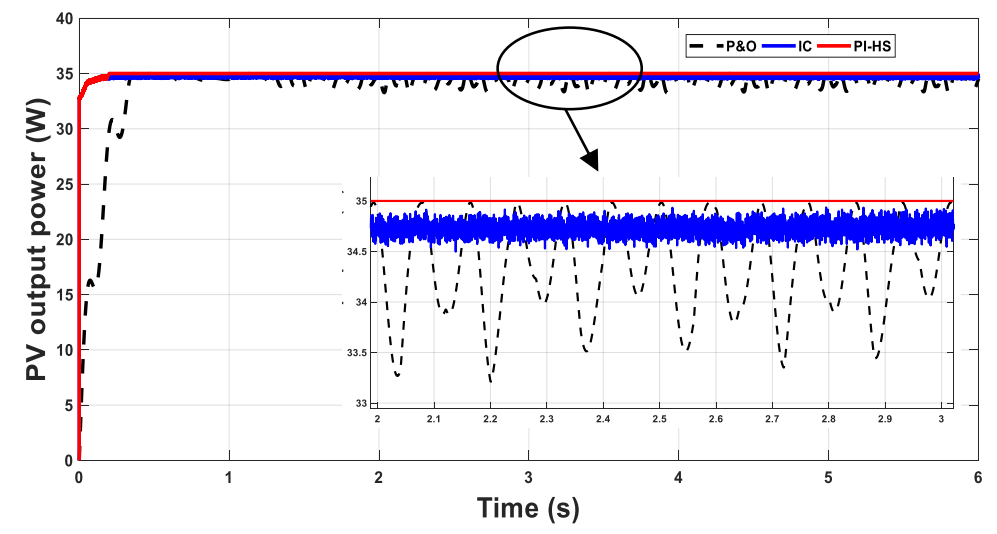

Fig. $6 \mathrm{MPP}$ at $25^{\circ} \mathrm{C}$ and $1000 \mathrm{~W} / \mathrm{m}^{2}$.

The performance of the proposed system will be investigated with some changes in environmental conditions. A sudden change in the temperature from 37 to $31{ }^{\circ} \mathrm{C}$ and a sudden change in irradiance from 1000 to $800 \mathrm{~W} / \mathrm{m}^{2}$ (change from point 30 to point 22 in Table 2) is taken place at $1.17 \mathrm{~s}$. The proposed technique gives better performance than $\mathrm{P} \& \mathrm{O}$ and IC techniques in both steady state and transient intervals, Fig.7.

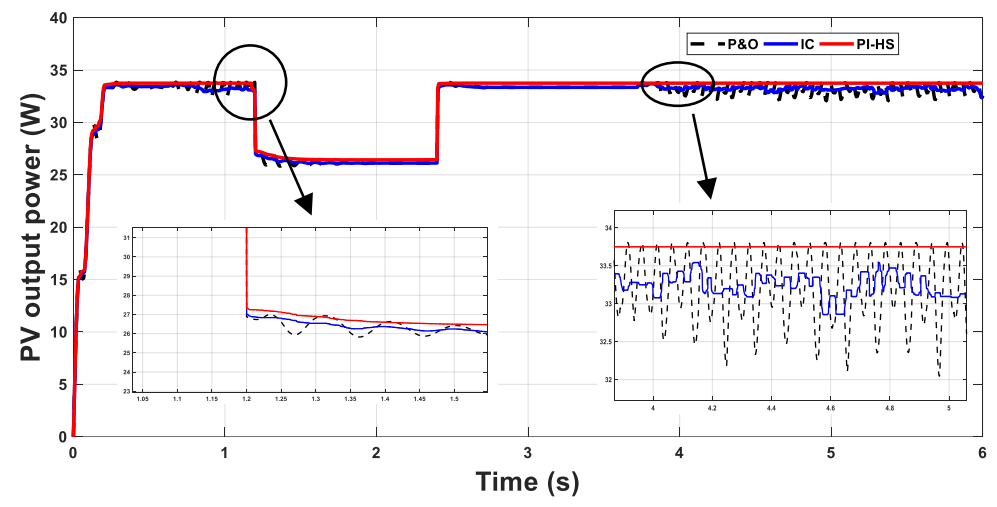

Fig.7 MPP with change from point 30 to point 22, defined in Table 2.

The PI controller introduced in this article succeeded in achieving the MPPT with better performance. Another test case will be introduced to check if the optimal PI controller parameters determine at certain conditions will satisfy the optimality at other operating conditions or not.

The standard test case (point 26) will be tested with two different values for the optimal PI controllers. The first PI controller, PI-HS-1 is the optimal controller parameters determined at the standard condition (2.497, 13.986), while the second controller PI-HS-2 is the PI control parameters at another point, point 24 as an example, with PI controller parameters of $(8.486,12.548)$. The PI controller parameters obtained for this case showed better performance and tracking the MPP to a higher level when using PI-HS-1 at which the 
operating conditions are considered than using PI-HS-2. This calls for changing the PI control parameters for each operating condition Fig.8. In other words, convert the fixed PI controller parameters into variable ones based on the environmental conditions. This transformation is difficult to be applied practically. This issue had been addressed by adding another technique to the system and implement it practically.

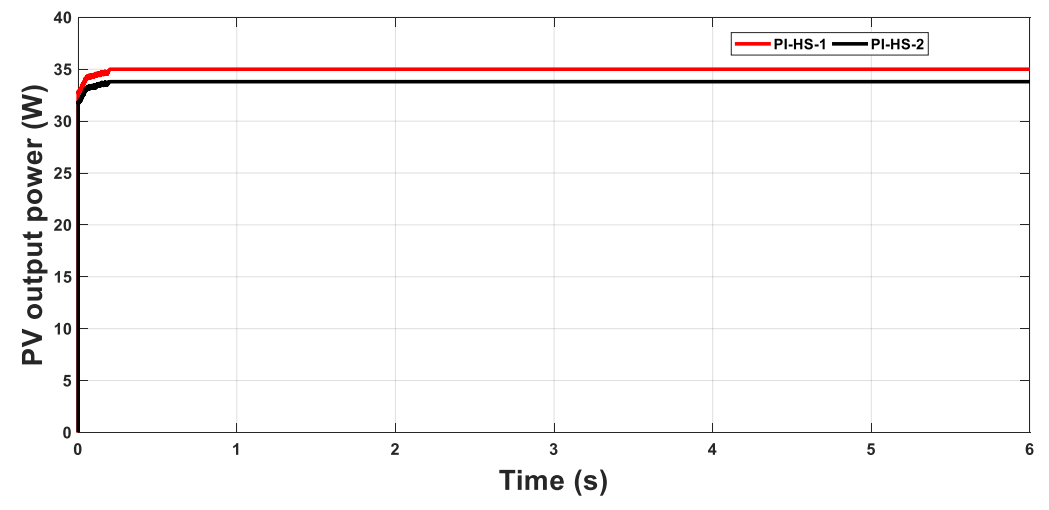

Fig.8 MPPT with fixed and variable PI-HS

\section{Testing the proposed MPPT algorithm}

The modification technique applied practically is done by determining the duty cycle required for MPPT corresponding to each operating condition. In other words, the output of PI-HS is determined at each point in Table 2. A new table is formed with the temperature, irradiance and the corresponding duty cycle. This technique is working without using PI controllers, which simplify the system and make it easy to implement. In order to test the proposed technique for adaptive MPPT, a test setup was developed that was capable of data acquisition in real-time with parameter recording functionality. The block diagram of the system is shown the Fig 9.

The block diagram shows the logical connections of different blocks of the system. Si-420TC irradiance sensor is used to sense light, which provides 4-20mA current output, and is compensated by built in thermal compensator. Moreover, it has a wide range of spectral response from 0 to $1200 \mathrm{~W} / \mathrm{m}^{2}$. Besides, three-wire RTD is used to monitor the temperature of solar panels in a wide range with high accuracy. Furthermore, National Instruments robust and precise current and voltage sensing modules NI9217 and NI9225 are used to monitor input and output parameters. For high frequency, PWM National Instrument X-series card is used which has $100 \mathrm{MHz}$ on board time base for accurate duty cycle control and frequency generation. 


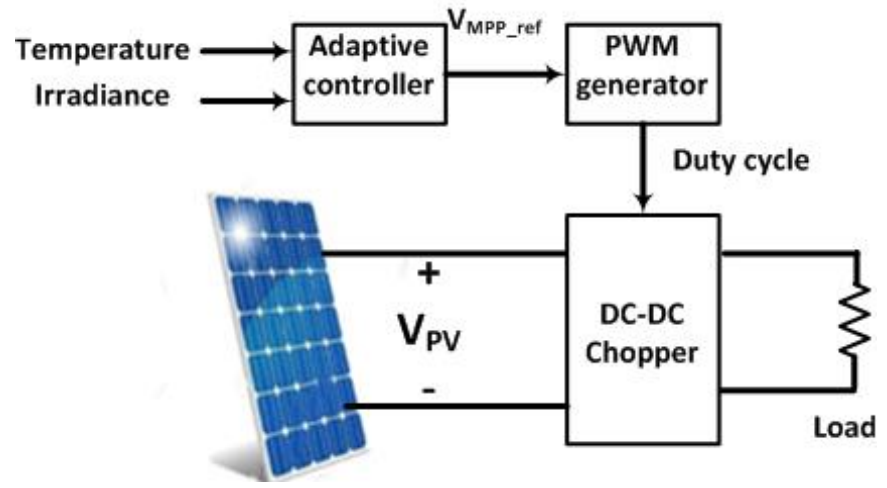

Fig.9 Block diagram of setup system

The switching circuit is based on a single MOSFET DC-DC buck topology. N-Channel MOSFET is used on high side. Since the gate is at a higher voltage level, a gate driver circuit is used to drive the MOSFET with respect to floating ground. Line Fuses are used on both sides of the circuit for protection. A voltage sensor was placed to put recording the input and output values. The schematic is shown in Fig.10.

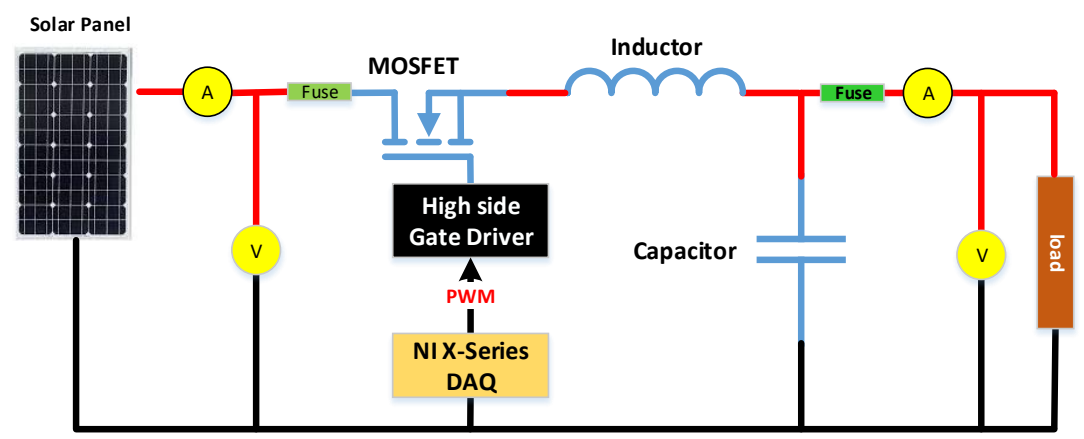

Fig.10 MOSFET switching circuit

The list of components used along with their values is given in Table 3.

Table 3: List of components for buck convertor

\begin{tabular}{|c|c|c|}
\hline Parts & Manufacturer & $\begin{array}{c}\text { Value/ } \\
\text { Part number }\end{array}$ \\
\hline Inductor & Murata & $1 \mathrm{mH}$ \\
\hline Capacitor & Murata & $1 \mathrm{uF}$ \\
\hline MOSFET & International Rectifier & IRF3205 \\
\hline Load & Bourns & Variable \\
\hline MOSFET driver & International Rectifier & IR2102 \\
\hline
\end{tabular}


Experimental test rig outdoor atrium in shown Fig.11. A solar panel is mounted at an optimum angle to get the maximum light at peak hours. An irradiance sensor is mounted at the same angle as the solar panel to get an accurate response. A temperature sensor is placed on the solar panel to get the current temperature of the panel and find out its dependency on the temperature.

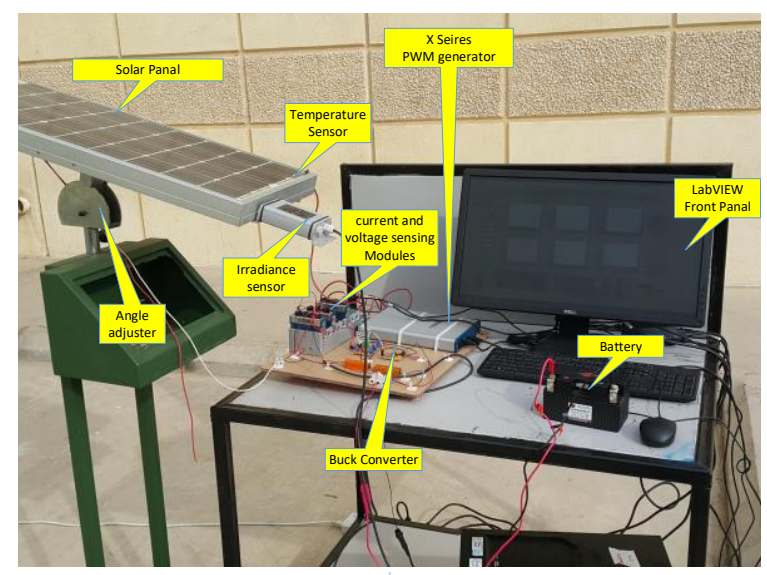

Fig.11 Experimental test ring

LabVIEW is used to develop the main software to test the proposed adaptive algorithm. LabVIEW Front panel shows input and output voltage; temperature, irradiance and power. The front panel is shown in Fig.12.

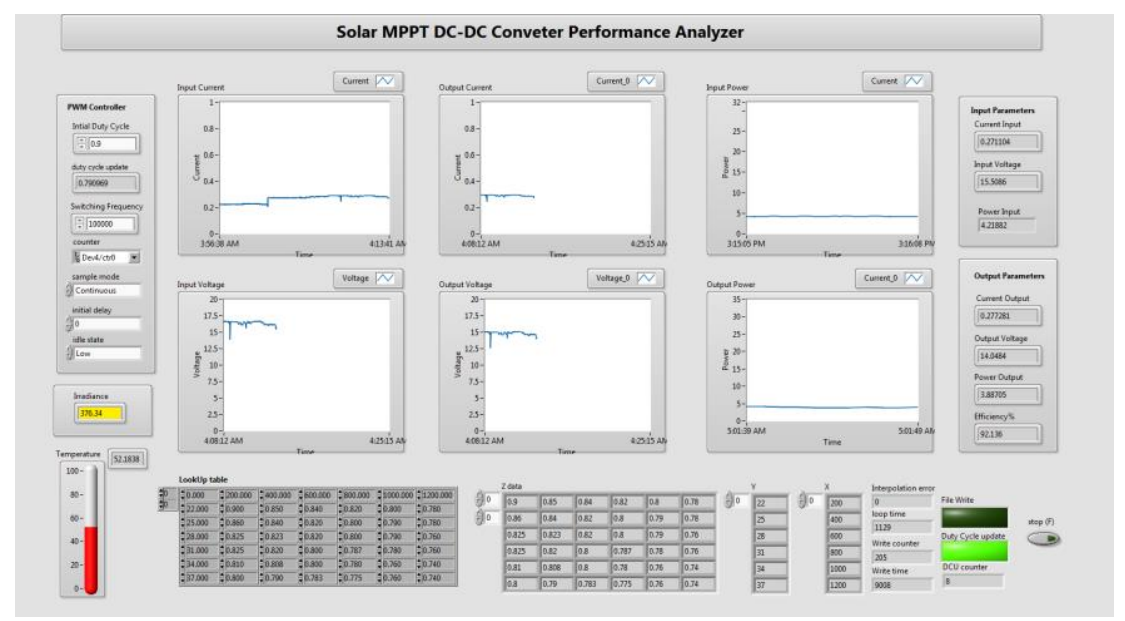

Fig.12 LabVIEW front panel

The test ring is left for one day for about three minutes outdoor, the irradiance and the temperature are recorded as in Fig.13. 


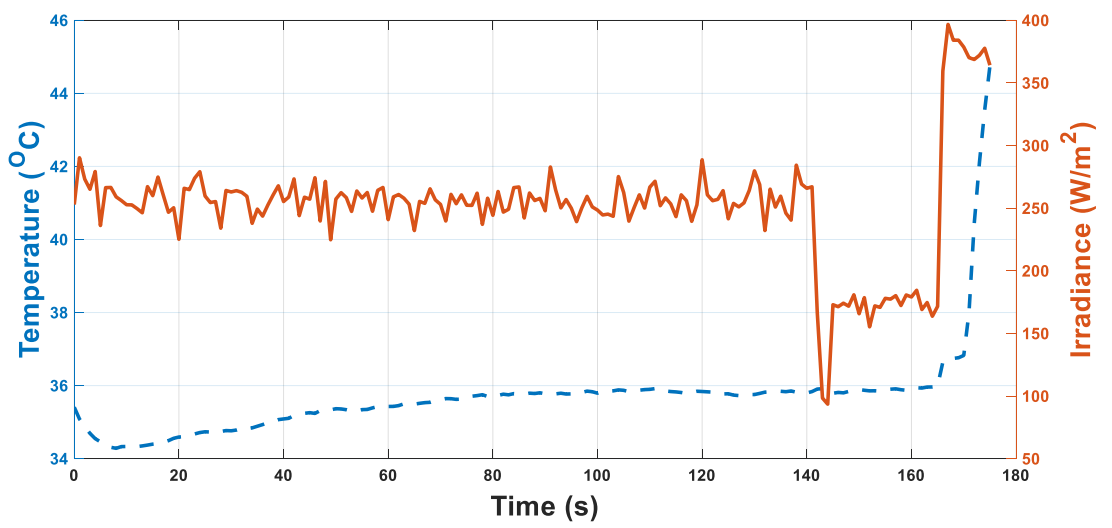

Fig.13 Temperature and irradiance variation in one day morning.

The system is tested with the proposed adaptive MPPT with an adaptive duty cycle and compared to a fixed duty cycle for driving the DC-DC chopper.

The input and output power for the same environmental conditions, Fig.13 are given in Fig.14. The system efficiency with this adaptive duty cycle is improved with values greater than $90 \%$.

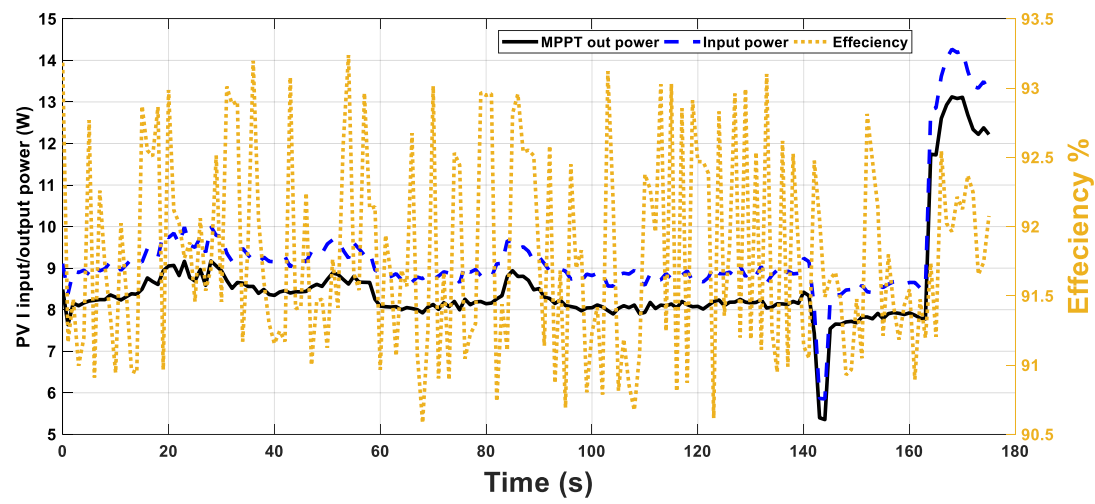

Fig.14 adaptive MPPT with temperature and irradiance variation in one day morning with efficiency.

Another practical test case for fixed duty cycles is applied and the efficiency of the system will be investigated. For a certain period, the input, output power of PV and the efficiency are recorded. The duty cycle in this case is kept at fixed values not adapted according to the proposed technique. Five values of duty cycles of $0.5,0.6,0.70 .8$ and 0.9 are adjusted at each interval, Fig.15. The system's maximum efficiency is $84 \%$ compared to the range of efficiencies between 91 to $93 \%$ when using the adaptive duty cycle as in Fig.14. 


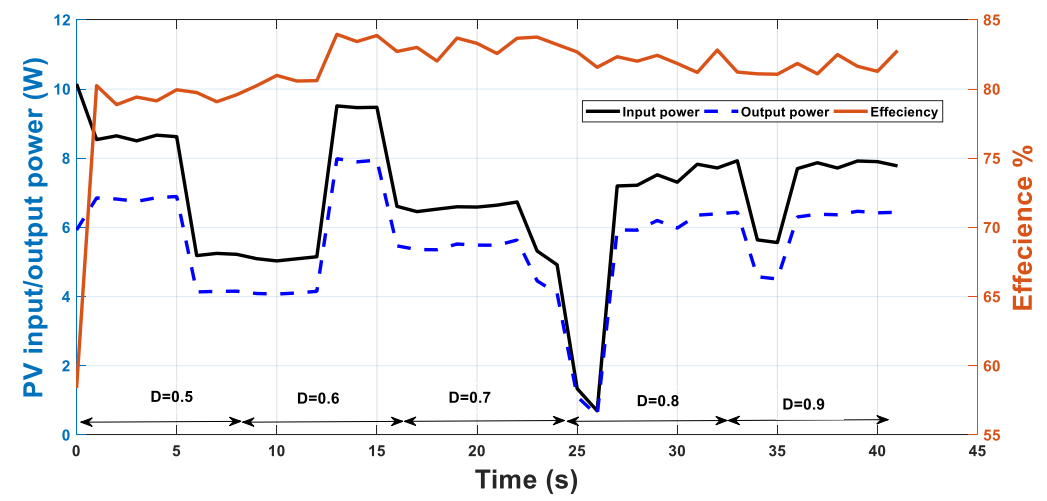

Fig.15 Fig.14 fixed MPPT with temperature and irradiance variation in one day morning with efficiency.

\section{Conclusions}

This paper introduced a new adaptive MPP technique for a standalone PV system. This technique is based on updating the reference voltage for MPPT based on the environmental changes including irradiance and temperature. This updated voltage is compared to the PV output voltage and the error is used to drive the DC-DC converter. This error is minimized by harmony search optimization technique. The proposed technique updated the PI controller parameters and consequently the duty cycle required for the converter. The proposed adaptive technique gave a better performance than $\mathrm{P} \& \mathrm{O}$ and IC techniques. An experimental setup is used to simplify the controller by lockup table consists of the temperature, irradiance and the corresponding duty cycle required for each operating condition for achieving MPPT. Compassion between the proposed adaptive and some fixed values for the duty cycles required for MPPT was introduced at every operating points. This comparison proved the effectiveness of the proposed method in MPPT with higher efficiencies.

\section{References}

[1] M. I. Mosaad, "Model reference adaptive control of STATCOM for grid integration of wind energy systems," in IET Electric Power Applications, vol. 12, no. 5, pp. 605-613, 5 2018, doi: 10.1049/ietepa.2017.0662. 
[2] Mohamed I. Mosaad and H.S. Ramadan "Power Quality Enhancement of Grid Connected Fuel Cell Using Evolutionary Computing Techniques: International Journal of Hydrogen, Volume 43, Issue 25, 21 June 2018, Pages 11568-11582.

[3] Ahmed K. Abdelsalam ; Ahmed M. Massoud ; Shehab Ahmed ; Prasad N. Enjeti "High-Performance Adaptive Perturb and Observe MPPT Technique for Photovoltaic-Based Microgrids" IEEE TRANSACTIONS ON POWER ELECTRONICS, VOL. 26, NO. 4, APRIL 2011,pp.1010-1021.

[4] Mohamed I.Mosaad, M. Osama Abed El-Raouf, Mahmoud A.Al-Ahmar, Fahmy M.El Bendary, "Optimal PI Controller of DVR to Enhance the Performance of Hybrid Power System Feeding a Remote Area in Egypt" Sustainable Cities and Society, Volume 47, May 2019, 101469 ,2019 pp.101469-101484.

[5] PV Power Plants Industry Guide [Online]. Available: http://www.PV resources.com.

[6] Y.C.Kuo, T.J.Liang and J.F.Chen, "Novel maximum-power point tracking controller for photovoltaic energy convertion system,” IEEE Indust.Electron. Trans.vol.48 (3), pp.594-601, 2001.

[7] W. Xiao and W.G.Dunford, "A modified adaptive hill climbing MPPT method for photovoltaic power systems," proc.35 Th Annu. IEEE Power Electron. Spec. Conf. pp.1957-1963, 2004.

[8] T. Esram and P. L.Chapman, "Comparison of photovoltaic array maximum power point tracking techniques," IEEE Trans. Energy Conv., vol. 22, no. 2, pp. 439-449, Jun. 2007.

[9] P. J. Wolfs and L. Tang, "A single cell maximum power point tracking converter without a current sensor for high performance vehicle solar arrays," in Proc. IEEE 36th Power Electron. Spec. Conf., Jun. 16-16,

[10] 2005, pp. 165-171.R. Gules, J. De Pellegrin Pacheco, H. L. Hey, and J. Imhoff, “A maximum power point tracking system with parallel connection for PV stand-alone applications,” IEEE Trans. Ind. Electron., vol. 55, no. 7, pp. 2674-2683, Jul. 2008.

[11] H. Patel and V. Agarwal, "Investigations into the performance of photovoltaics-based active filter configurations and their control schemes under uniform and non-uniform radiation conditions," IET Renewable Power Gener., vol. 4, no. 1, pp. 12-22, Jan. 2010.

[12] L. Zhang, A. Al-Amoudi, and Y. Bai, "Real-time maximum power point tracking for grid-connected photovoltaic systems," in Proc. 8th Int. Conf. Power Electron. Variable Speed Drives (IEE Conf. Publ. No. 475), 2000, pp. $124-129$.

[13] H. Patel andV.Agarwal, "MPPT Scheme for a PV-fed single-phase singlestage grid-connected inverter operating in CCM with only one current sensor,” IEEE Trans. Energy Convers., vol. 24, no. 1, pp. 256-263, Mar. 2009.

[14] 37 M.-L. Chiang, C.-C. Hua, and J.-R. Lin, “Direct power control for distributed PV power system," in Proc. Power Convers. Conf., Osaka, Japan, 2002, pp. 311-315.

[15] W. Xiao and W. G. Dunford, "A modified adaptive hill climbing MPPT method for photovoltaic power systems," in Proc. IEEE 35th Annu. Power Electron. Spec. Conf., Jun. 20-25, 2004, vol. 3, pp. 1957-1963.

[16] P. J. Wolfs and L. Tang, "A single cell maximum power point tracking converter without a current sensor for high performance vehicle solar arrays," in Proc. IEEE 36th Power Electron. Spec. Conf., Jun. 16-16, 2005, pp. 165-171. 
[17] Pandey, N. Dasgupta, and A. K. Mukerjee, "High-performance algorithms for drift avoidance and fast tracking in solar MPPT system,” IEEE Trans. Energy Convers., vol. 23, no. 2, pp. 681-689, Jun. 2008.

[18] S. Easter Selvan, Sethu Subramanian, S. Theban Solomon, Novel Technique for PID Tuning by Particle Swarm Optimization, in Proc.7th Annul. Swarm Users/Researchers Conf. (Swarm Fest 2003), Notre Dame, IN, 2003.

[19] T. Markvart, Solar Electricity, John Wiley \& Sons, 1994.

[20] G. Walker, "Evaluating MPPT converter topologies using a MATLAB PV model," Journal of Electrical \& Electronics Engineering, Australia, IEAust, vol.21, No. 1, 2001, pp.49-56.

[21] M. Reynolds and M. A. Frye, "Free -flight odor tracking in Drosophila is consistent with an optimal intermittent scale-free search." PloS one. 2, e.354, 2007.

[22] X.-S. Yang, S. Deb, “Cuckoo search via L'evy flights”, in: Proc. Of World Congress on Nature \& Biologically Inspired Computing (NaBIC 2009), December 2009, India. IEEE Publications, USA, pp. 210-214 (2009).

[23] Yang X-S, Deb S. Multiobjective cuckoo search for design optimization. Comput oper Res 2011.

[24] X.S. Yang Nature-inspired metaheuristic algorithms, luniver, (2008).

[25] Viagundamoorthi M, Ramesh Experimental investigation of chaos in input regulated solar PV powered cuk converter. Int J compute APPL 2012; 34:11-6.

[26] Mohamed I. Mosaad, Nagy I. Elkalashy and Mohamed G. Ashmawy, "Integrating Adaptive Control of Renewable Distributed Switched Reluctance Generation and Feeder Protection Coordination “ Electric Power System Research journal, Elsevier, Volume 154, January 2018, Pages 452-462.

[27] M. Z. Alabedin, E. F. El-Saadany and M.M.A. Salama, "Maximum power point tracking for photopholtaic systems using fuzzy logic and artificial neural networks,” IEEE power and Energy Soc. Gen. Meet.pp.1-9, 2011.

[28] S.-H. Park, G.-R. Cha,Y.-C. Jung, and C.-Y.Won, "Design and application for PV generation system using a soft-switching boost converter with SARC," IEEE Trans. Ind. Electron., vol. 57, no. 2, pp. 515-522, Feb. 2010.

[29] Mohamed I. Mosaad ,M. Osama abed el-Raouf, Mahmoud A. Al-Ahmar, Fahd A. Banakher "Maximum Power Point Tracking of PV system Based Cuckoo Search Algorithm; review and comparison "Energy procedia , Volume 162, April 2019, Pages 117-126.

[30] Mohammed I. Mosaad, Ahmed Abu-Siada, Mohamed Elnaggar"Application of Superconductors to Improve the Performance of DFIG-based WECS” IEEE access journal, December 2019, Volume 7, Issue 1, pp103760103769. 
Figures

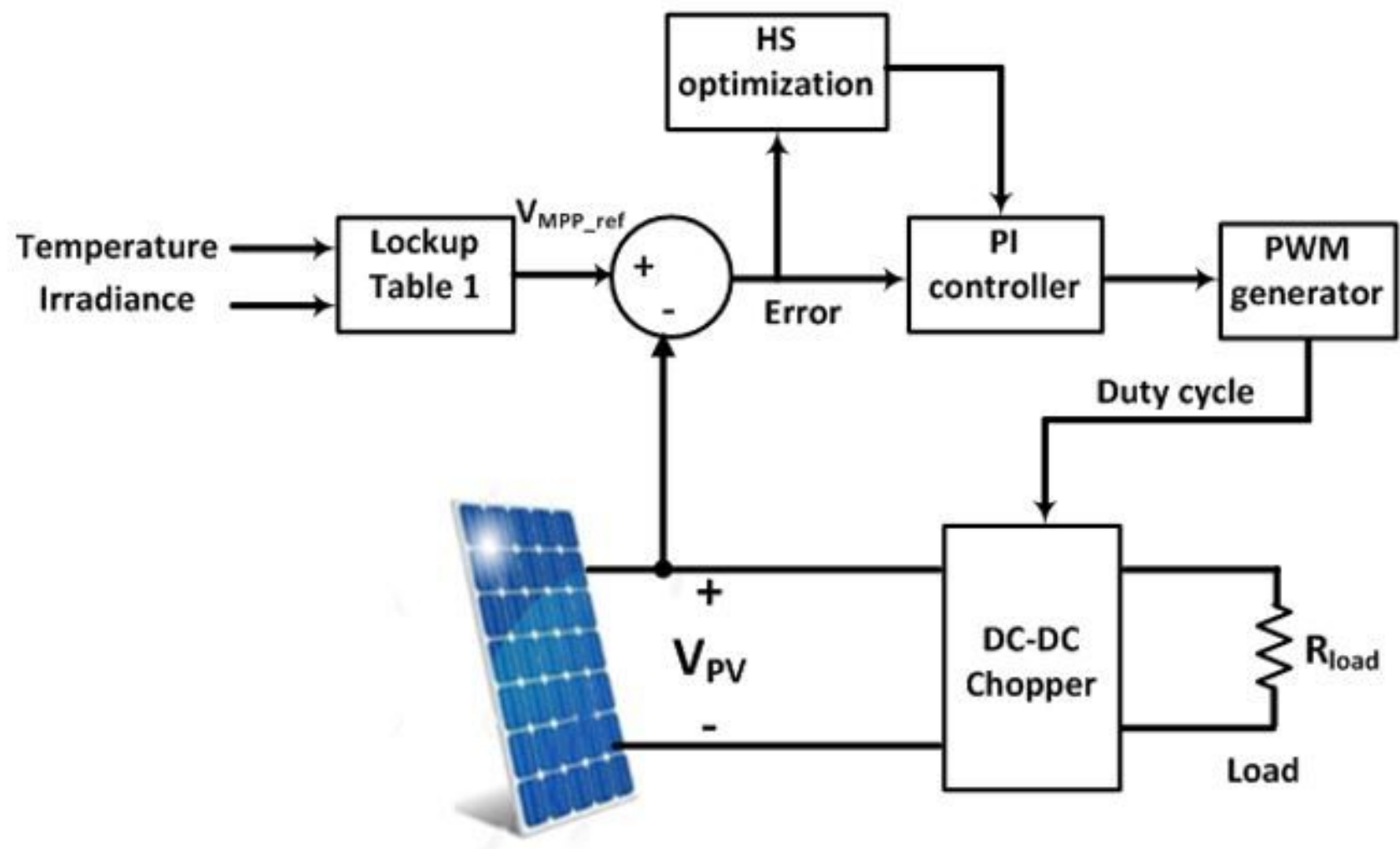

Figure 1

System under study.

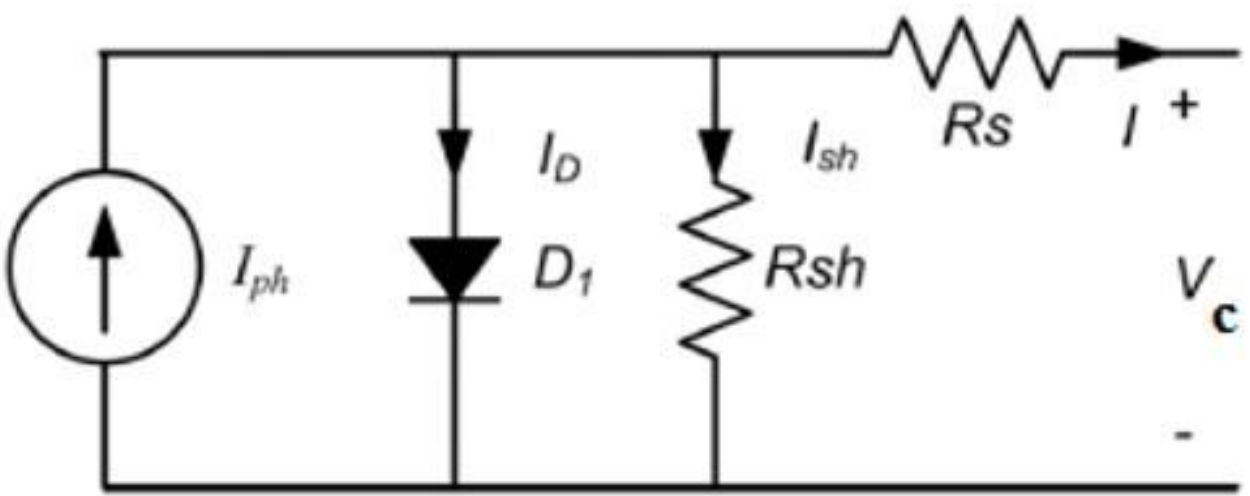

Figure 2

Solar cell equivalent circuit 


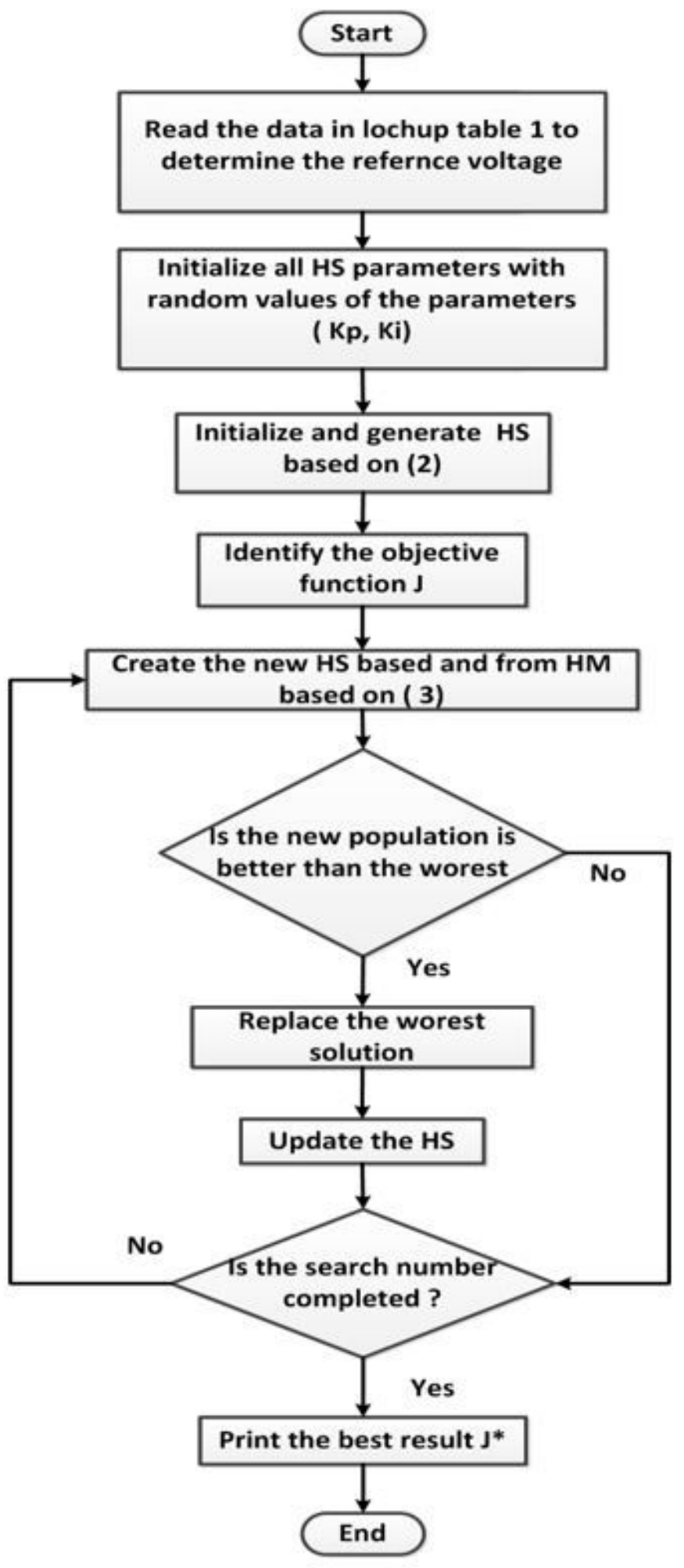

Figure 3

HS optimization flow chart. 

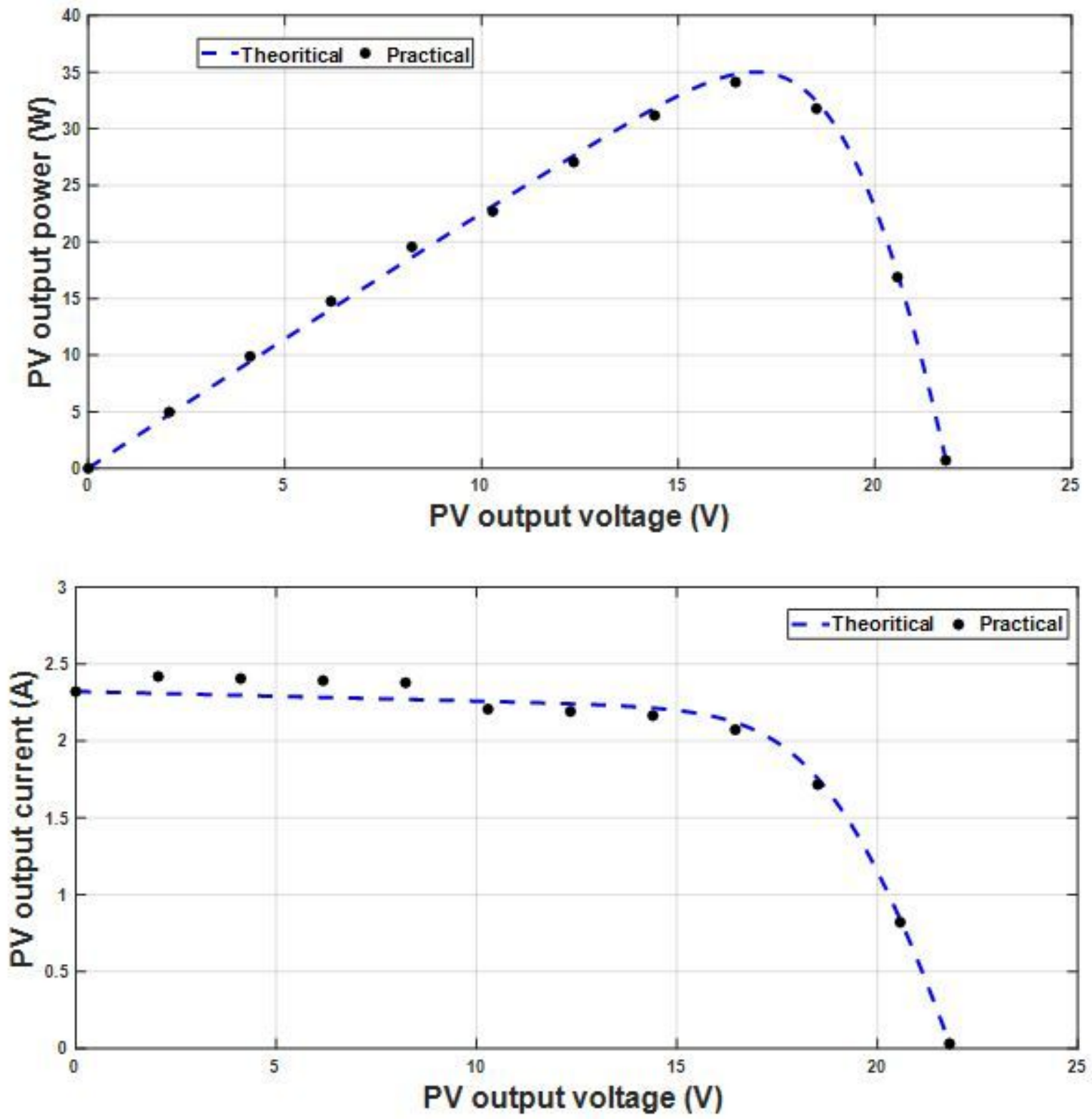

a- $\mathrm{P}-\mathrm{V}$ characteristics b- I-V characteristics

Figure 4

Experimental verification of solar cell characteristics. 


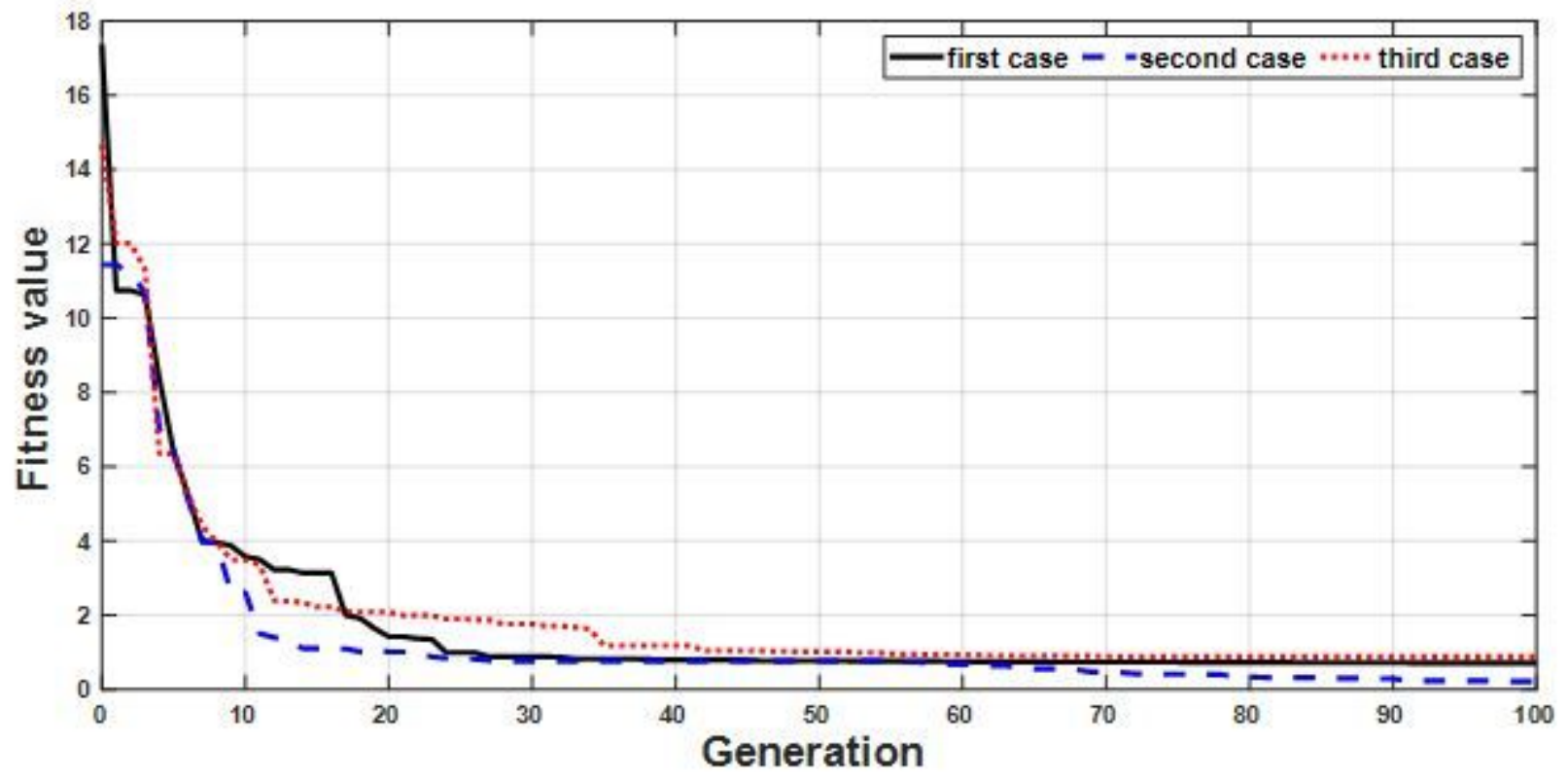

Figure 5

Convergence of objective function using HS

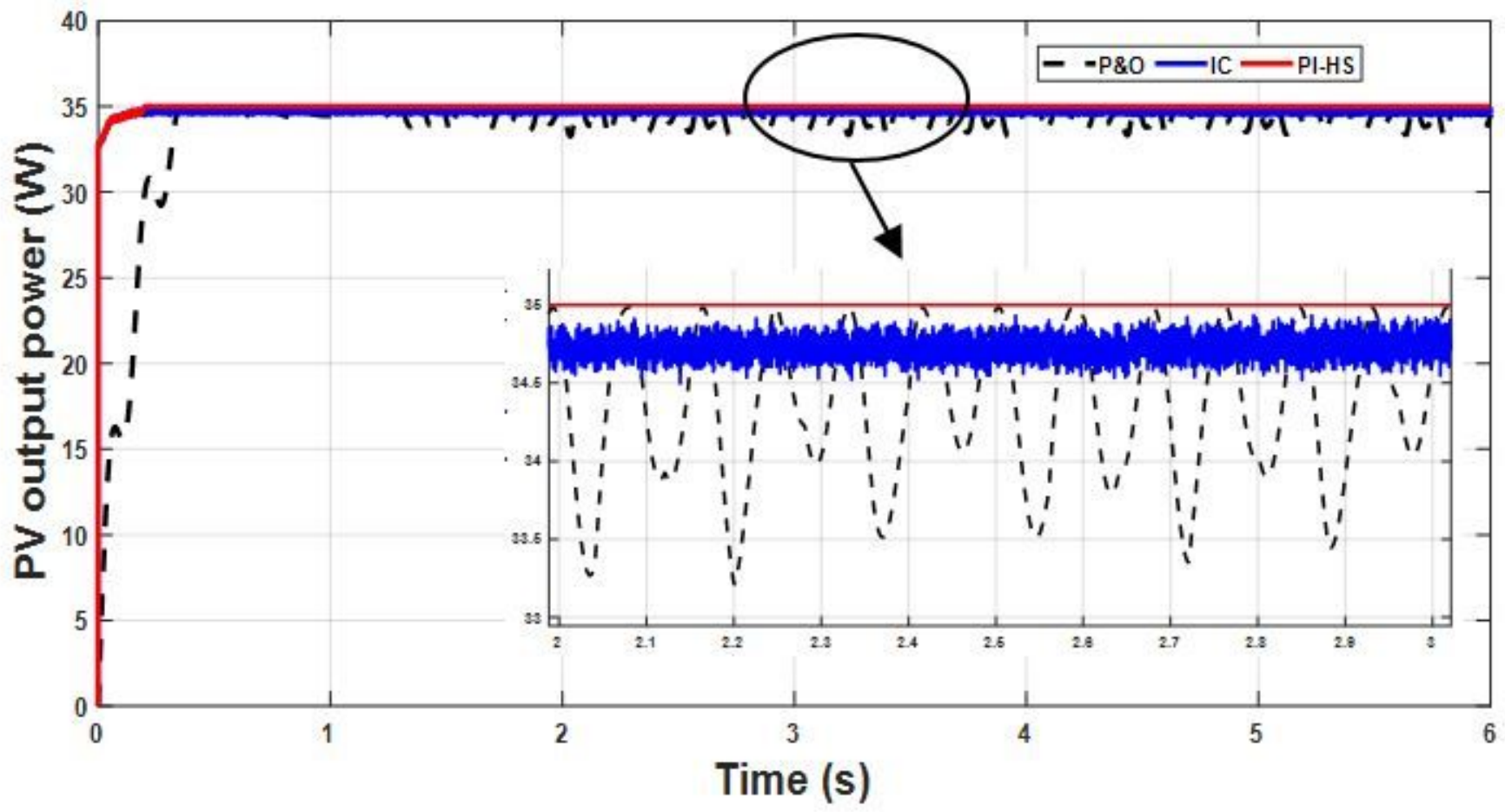

Figure 6

MPP at $25 \circ C$ and $1000 \mathrm{~W} / \mathrm{m} 2$. 


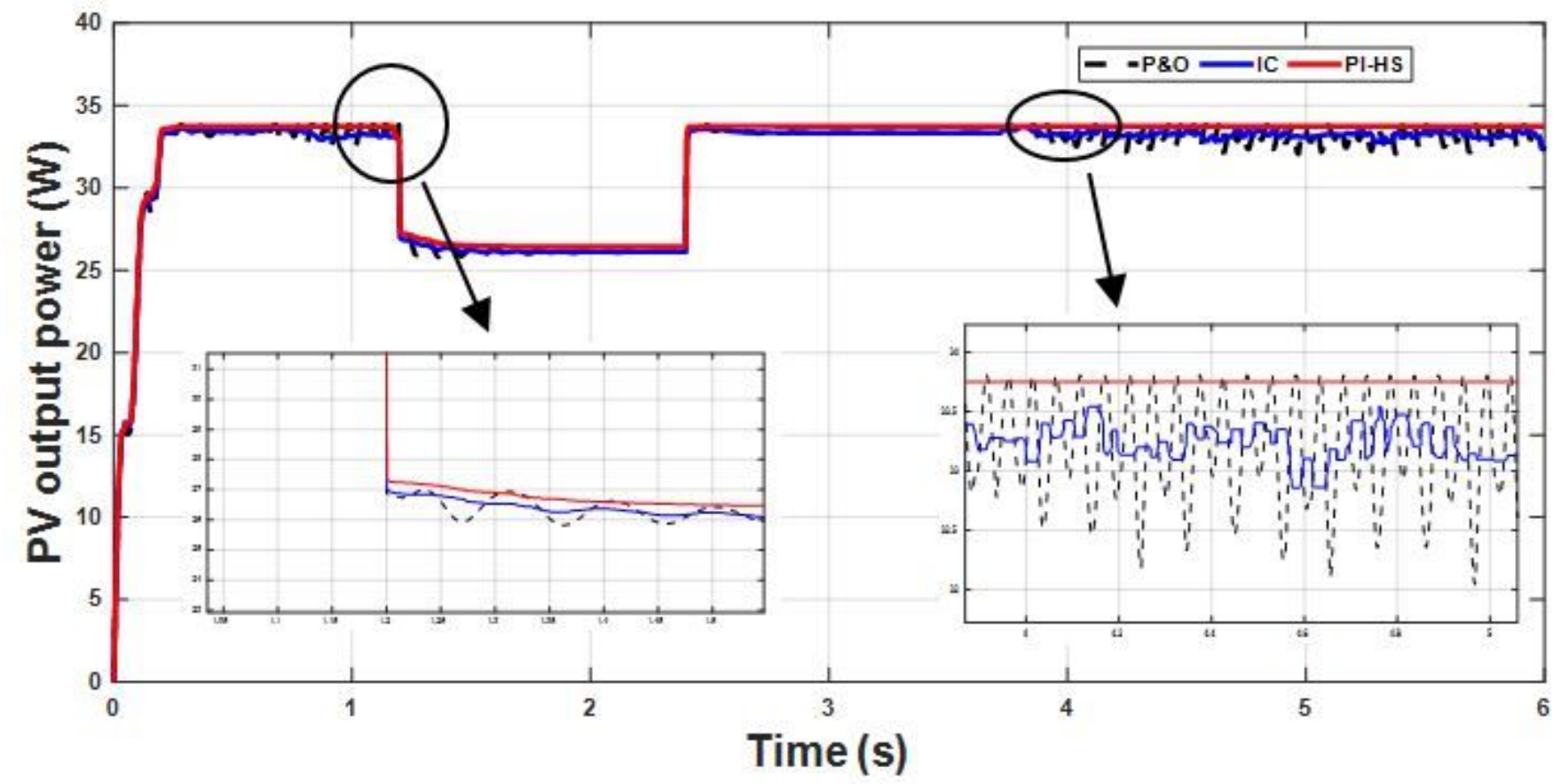

Figure 7

MPP with change from point 30 to point 22, defined in Table 2.

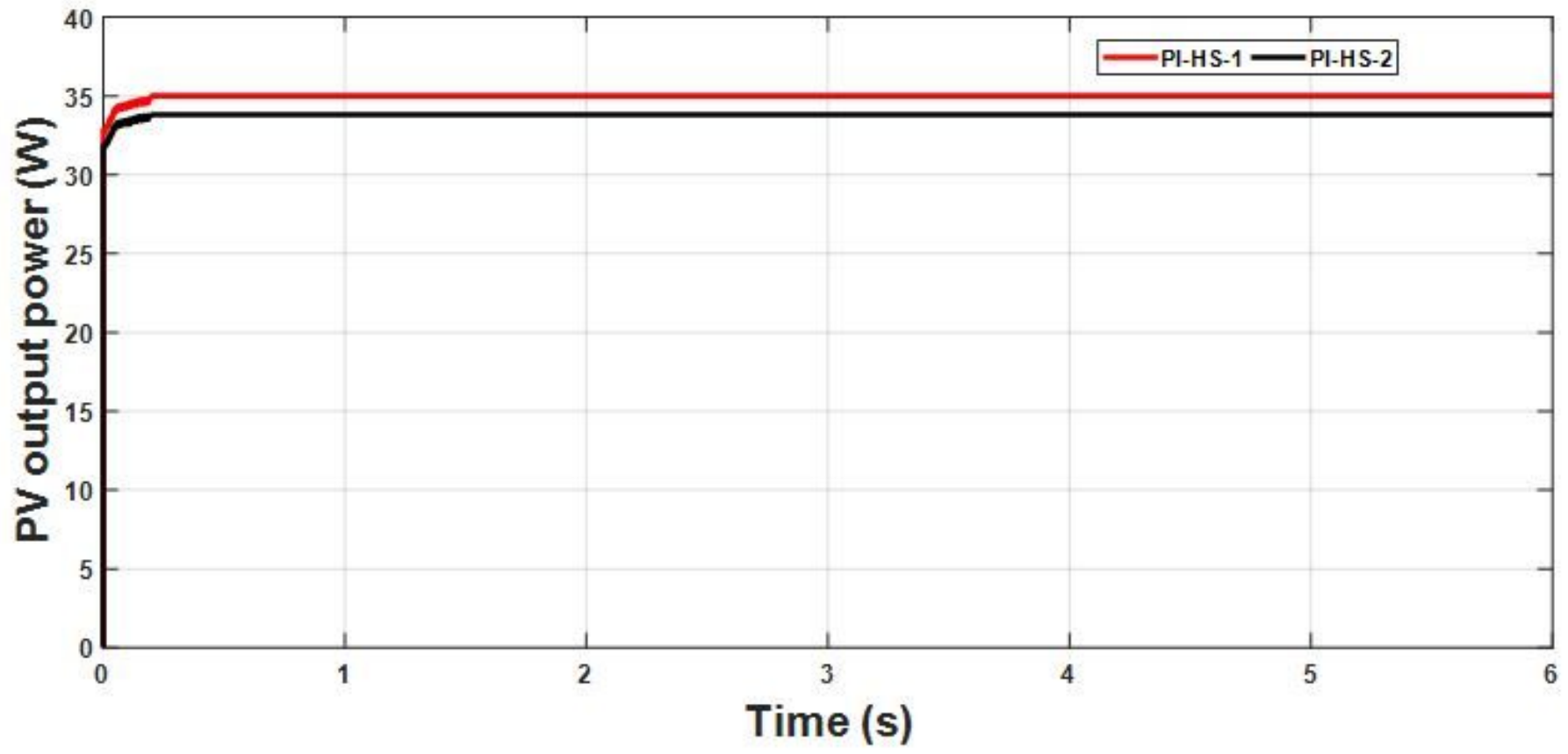

Figure 8

MPPT with fixed and variable PI-HS 


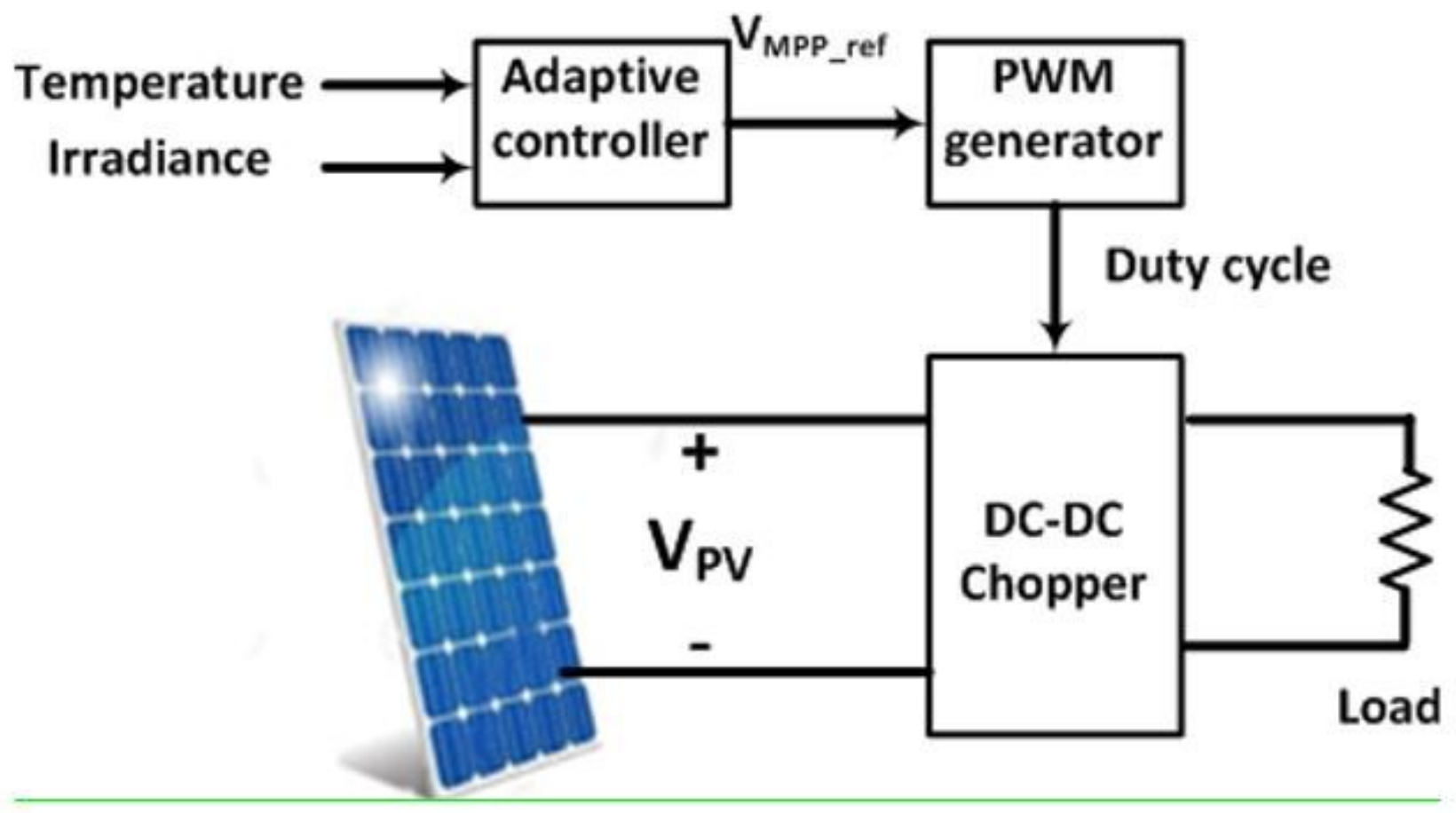

Figure 9

Block diagram of setup system

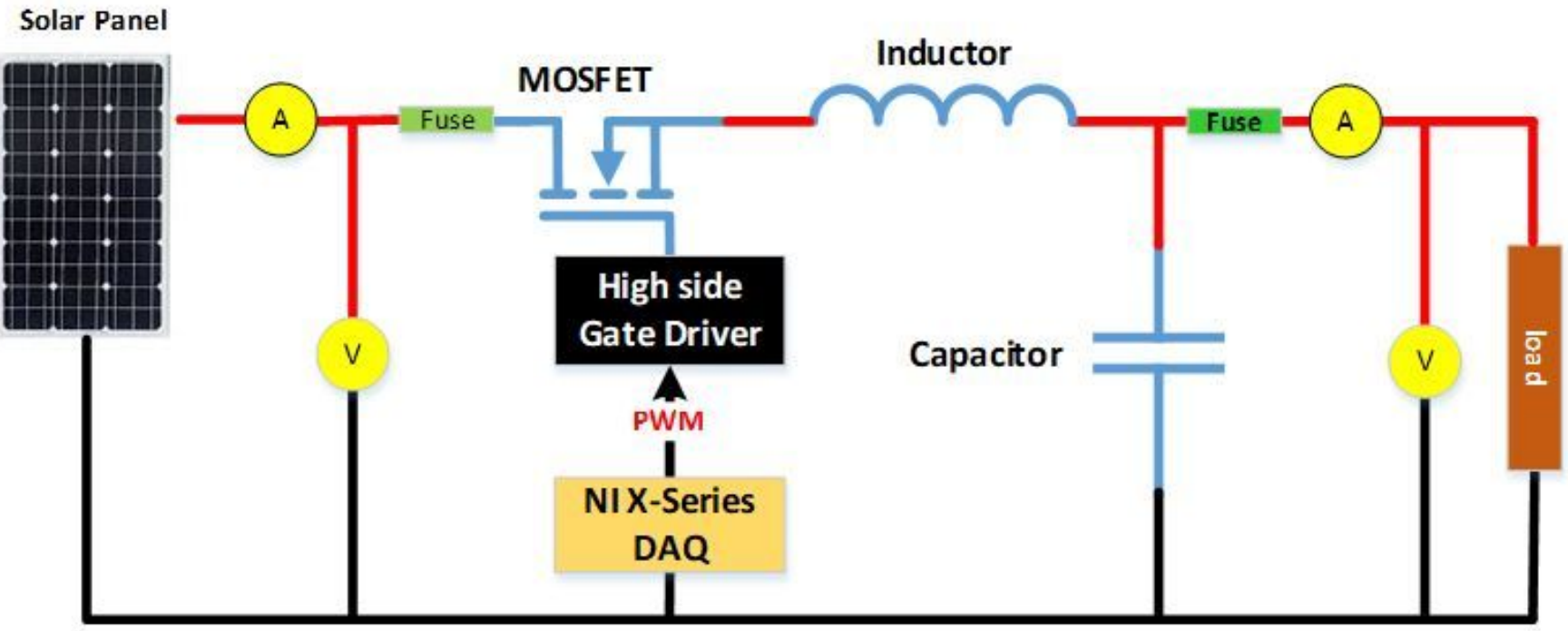

Figure 10

MOSFET switching circuit 


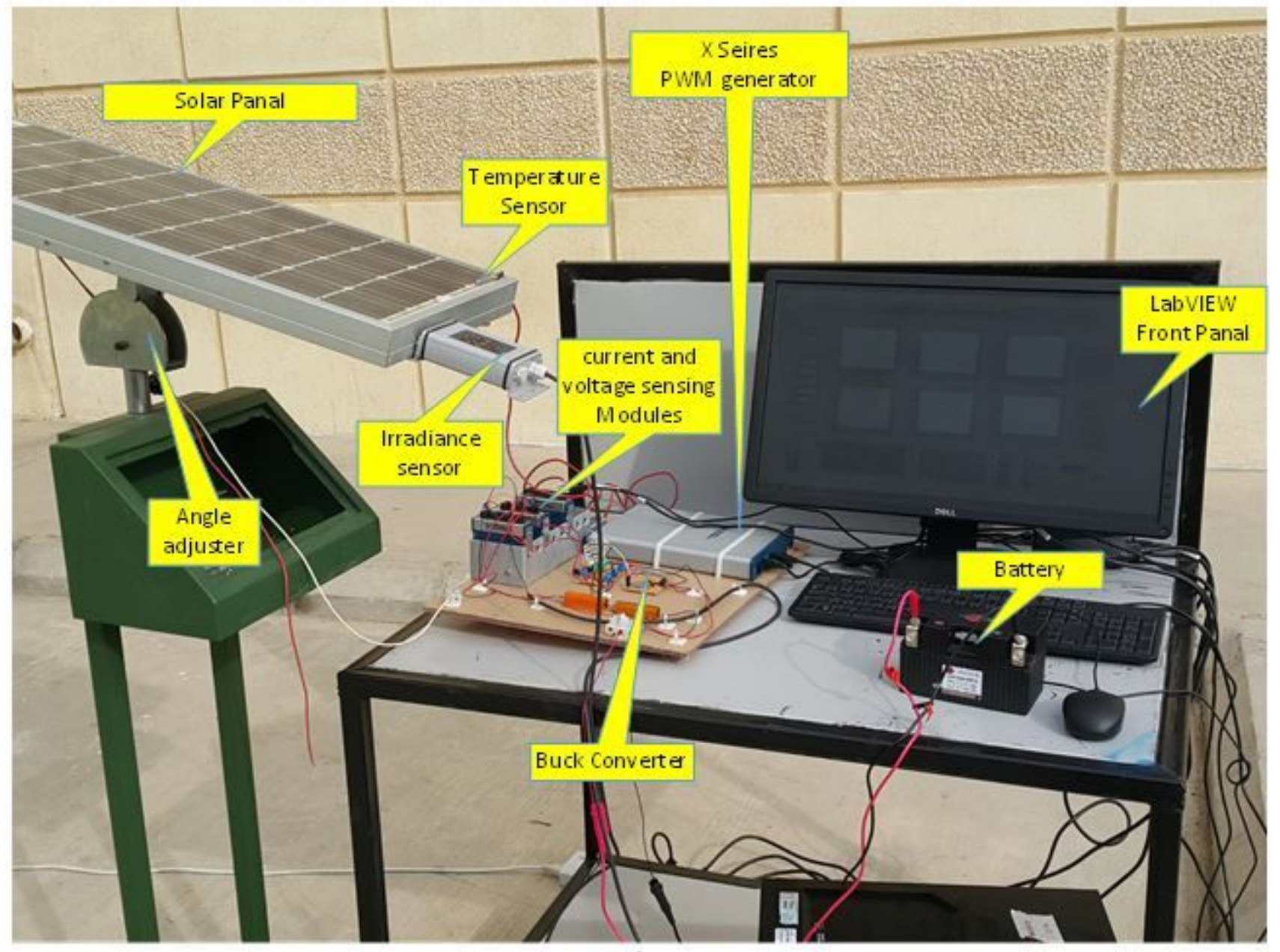

Figure 11

Experimental test ring 


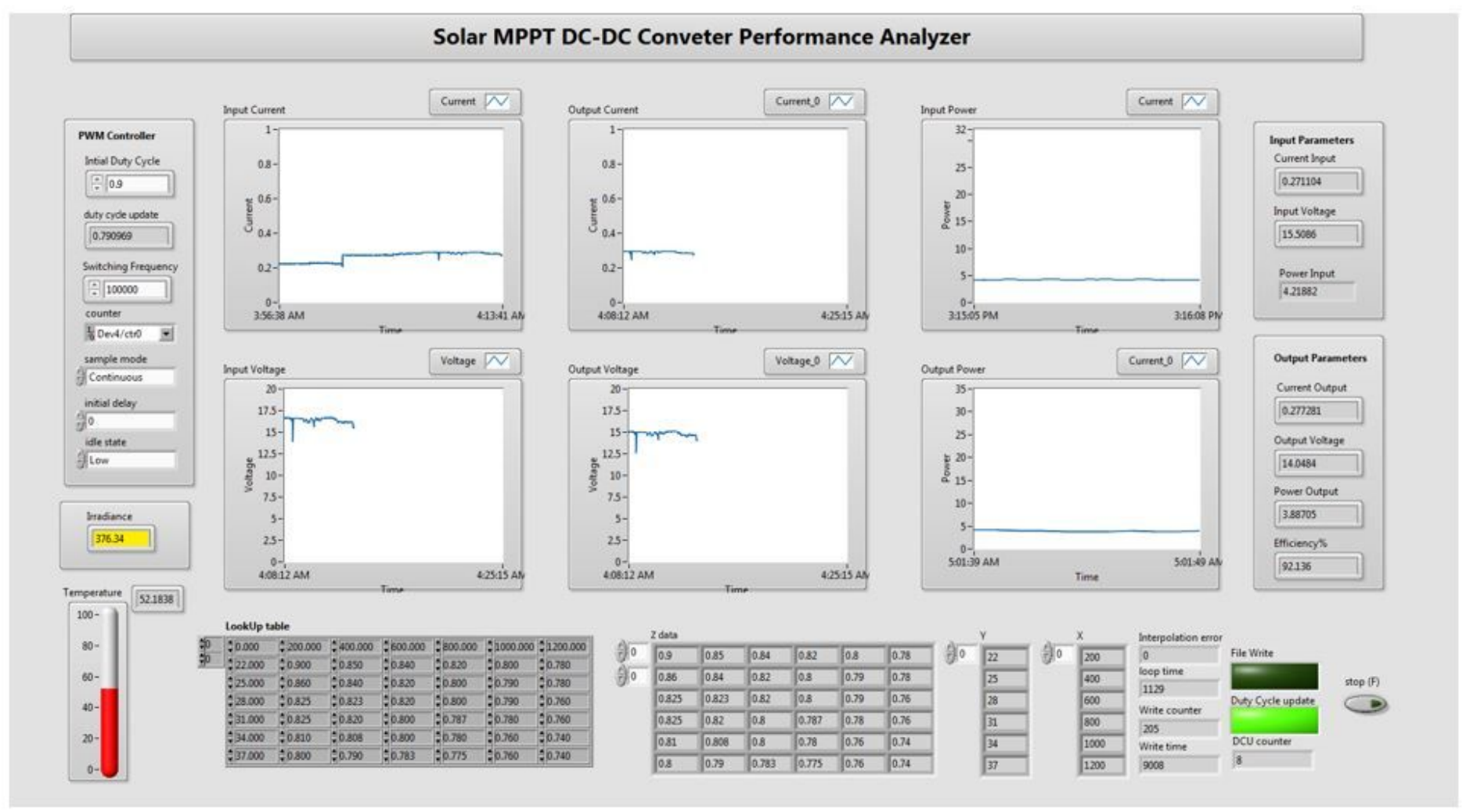

Figure 12

LabVIEW front panel

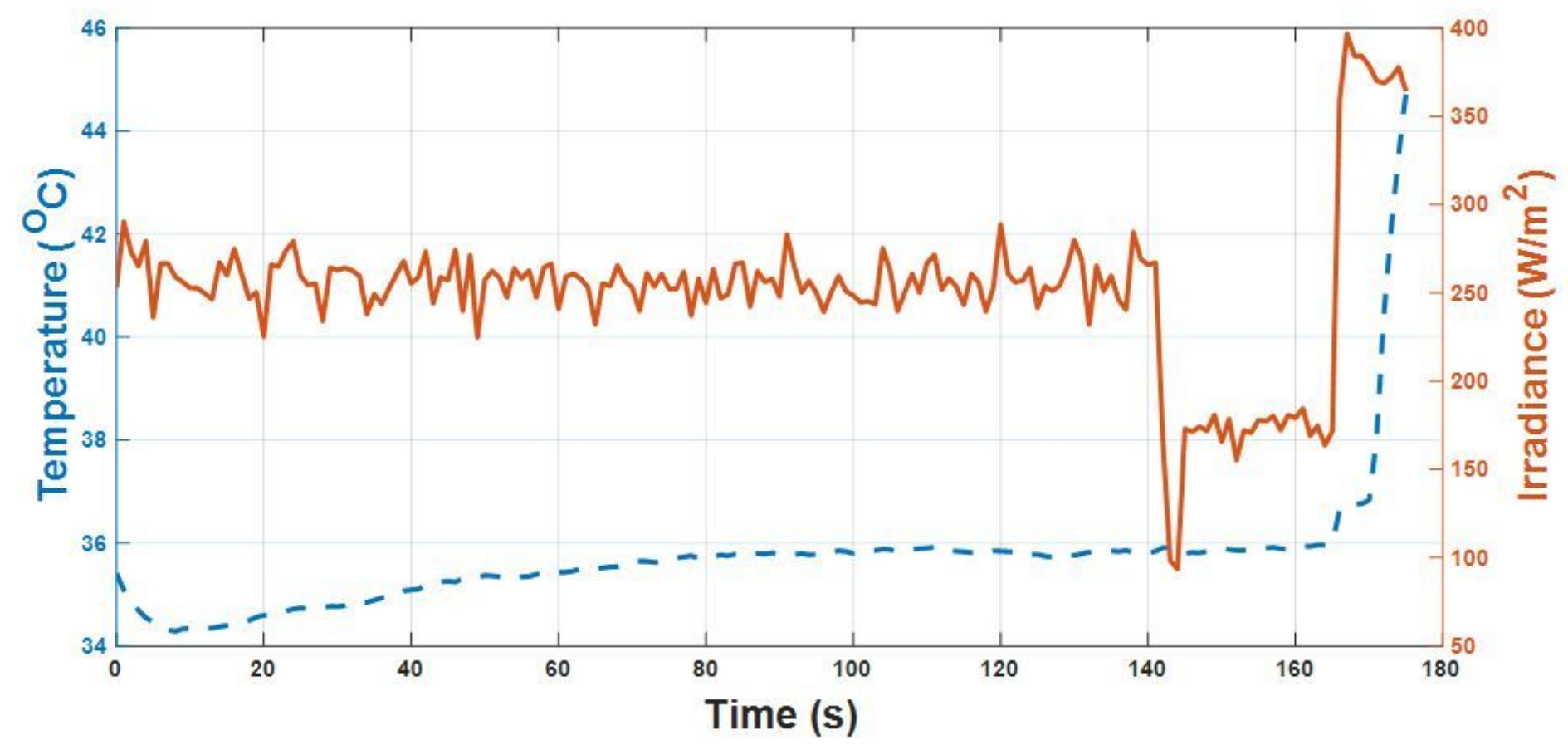

Figure 13 
Temperature and irradiance variation in one day morning.

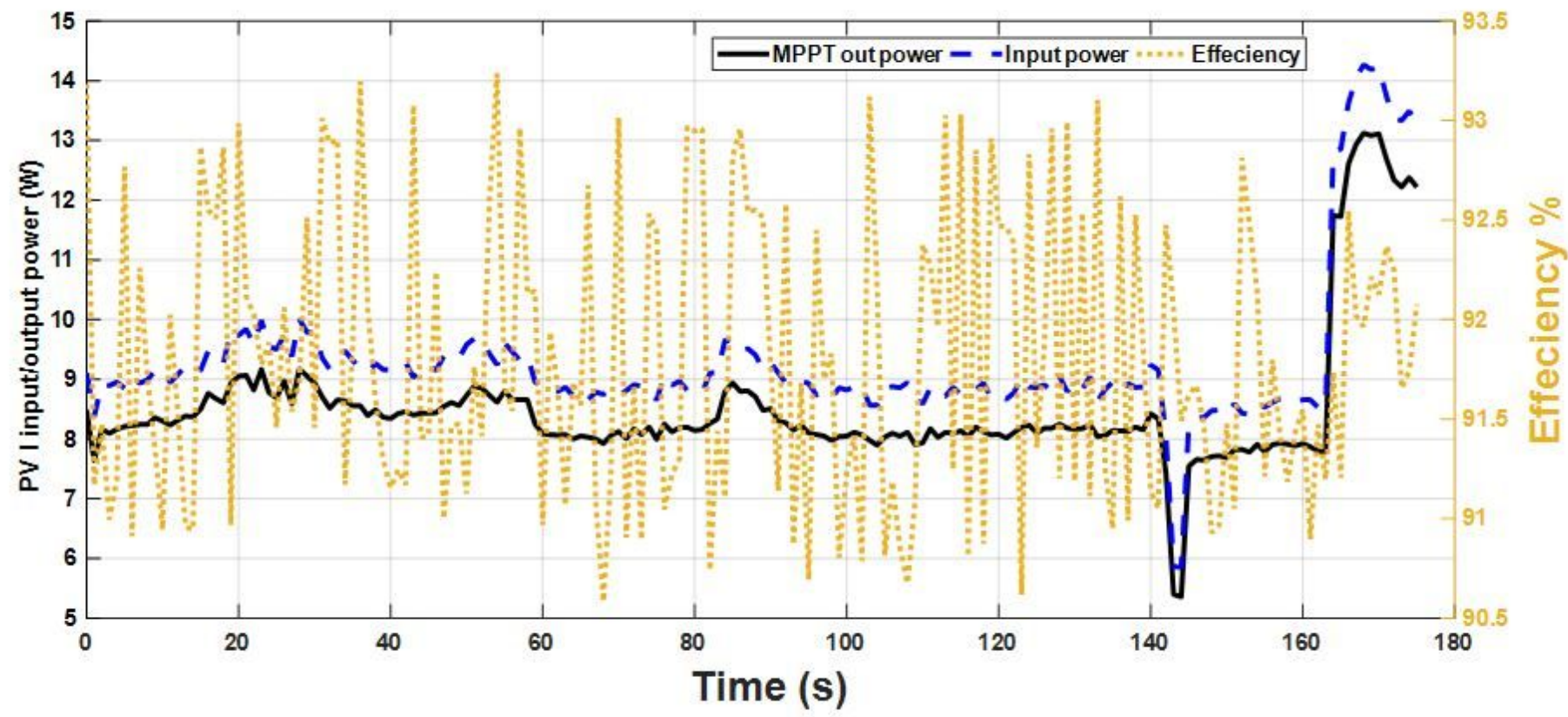

Figure 14

adaptive MPPT with temperature and irradiance variation in one day morning with efficiency.

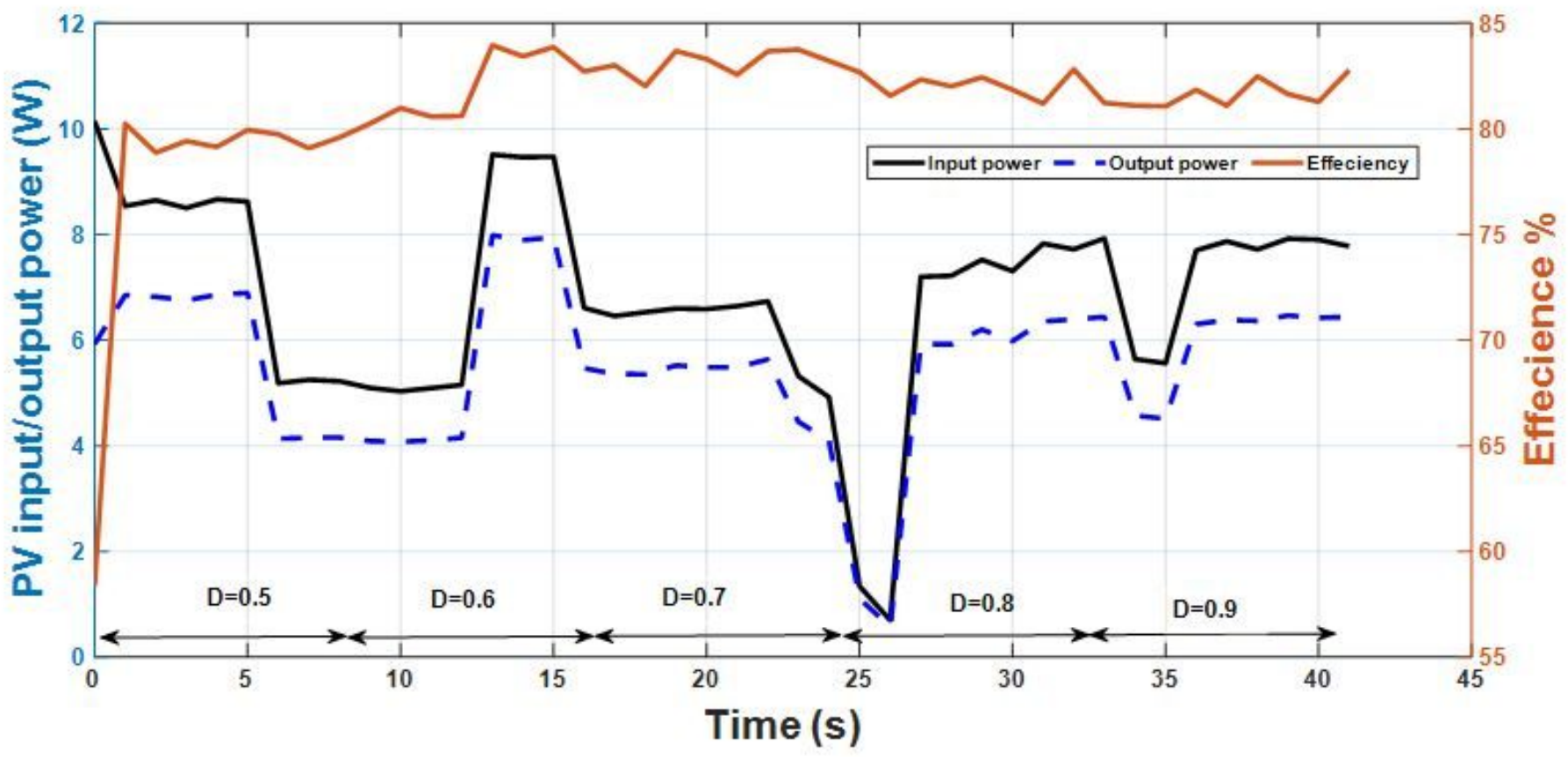

Figure 15

Fig.14 fixed MPPT with temperature and irradiance variation in one day morning with efficiency. 